\title{
Rational Design of Metal Oxide Solid Acids for Sugar Conversion
}

\author{
Atsushi Takagaki (D) \\ Department of Applied Chemistry, Faculty of Engineering, Kyushu University, 744 Motooka, Nishi-ku, \\ Fukuoka 819-0395, Japan; atakagak@cstf.kyushu-u.ac.jp; Tel.: +81-92-802-6711
}

Received: 15 October 2019; Accepted: 24 October 2019; Published: 29 October 2019

\begin{abstract}
Aqueous-phase acid-catalyzed reactions are essential for the conversion of cellulose-based biomass into chemicals. Brønsted acid and Lewis acid play important roles for these reactions, including hydrolysis of saccharides, isomerization and epimerization of aldoses, conversion of D-glucose into 5-hydroxymethylfurfural, cyclodehydration of sugar alcohols and conversion of trioses into lactic acid. A variety of metal oxide solid acids has been developed and applied for the conversion of sugars so far. The catalytic activity is mainly dependent on the structures and types of solid acids. Amorphous metal oxides possess coordinatively unsaturated metal sites that function as Lewis acid sites while some crystal metal oxides have strong Brønsted acid sites. This review introduces several types of metal oxide solid acids, such as layered metal oxides, metal oxide nanosheet aggregates, mesoporous metal oxides, amorphous metal oxides and supported metal oxides for sugar conversions.
\end{abstract}

Keywords: Sugars; cellulose; glucose; 5-hydroxymethylfurfural; lactic acid; solid acid; Brønsted acid; Lewis acid; metal oxide; water-tolerant catalyst

\section{Introduction}

The fundamental features of solid acid catalysts are the reusability of the catalysts, their easy separation from the products and solvents and unnecessary neutralization, which are beneficial to saving energy and cost. Besides these, special requirements of the catalysts for sugar conversion are high recognition ability of sugar molecules and high tolerance against water.

Sugars have complex structures with many functional groups, including carbonyl and hydroxyl groups. The change in positions of these functional groups offers different characteristics such as chemical reactivity and biological activity. Sugars are highly reactive and easily degraded; thus, many side reactions could occur, resulting in poor selectivity for the desired product in most cases. A suitable catalyst should interact with a specific position of the reactant.

Sugars have many hydroxyl groups and thus are soluble in water. For the conversion of sugars, polar solvents such as water, methanol, ethanol, $N, N$-dimethylformamide (DMF) and dimethyl sulfoxide (DMSO) are widely used. Among polar solvents, water is the most suitable solvent because these sugars can be obtained from cellulose and hemicellulose via hydrolysis in water and water itself is the green solvent [1]. However, water is not preferable for solid acid catalysts due to the following reasons. First, water molecules cover acid sites resulting in severe decrease in the catalytic activity which is typical for H-type zeolites. Second, water molecules generally cause loss of the Lewis acidity of solid catalysts. Third, water molecules may change or disrupt the crystal structure of solid catalysts due to their high polarity. For example, $\gamma-\mathrm{Al}_{2} \mathrm{O}_{3}$ alters its crystal structure into boehmite $\mathrm{AlO}(\mathrm{OH})$ in hot water (above $423 \mathrm{~K}$ ) [2].

Conventional solid acid catalysts, including zeolites, were mostly developed for oil refining in the last century. Reactants have less functional groups with non-polarity and are converted in gas-phase flow systems. These reaction conditions are very different from those of sugar conversion in the 
liquid phase. Before the development of solid acid catalysts for liquid-phase biomass conversion, water-tolerant solid acids were studied because reactions such as olefin hydration and ester hydrolysis necessitate water as a solvent in the petrochemical process and the importance of water as a solvent has been raised from the viewpoint of green chemistry [3]. As water-tolerant solid acid catalysts, hydrophobic zeolites [4,5], solid heteropolyacids such as $\mathrm{Cs}_{2.5} \mathrm{H}_{0.5} \mathrm{PW}_{12} \mathrm{O}_{40}$ [6], metal oxides including amorphous niobium oxide $\left(\mathrm{Nb}_{2} \mathrm{O}_{5} \cdot n \mathrm{H}_{2} \mathrm{O}\right)[7,8], \mathrm{MoO}_{3}-\mathrm{ZrO}_{2}$ [9] and metal phosphates including niobium phosphate [10] have been reported. Some of these water-tolerant solid acids are applicable for aqueous-phase sugar conversion. It should be noted that D-glucose formation from maltose hydrolysis using $\mathrm{Cs}_{2.5} \mathrm{H}_{0.5} \mathrm{PW}_{12} \mathrm{O}_{40}$ [11] and $\mathrm{HMF}$ formation from fructose dehydration using niobium phosphate [10] were already studied before the rapid growth of researches for biomass conversion using heterogeneous catalysts from 2006. In this review, D-glucose which is naturally obtained is simply described as glucose.

A variety of metal oxide solid acids was developed and applied for sugar conversions. The catalytic performance is mainly dependent on the types of solid acids. Amorphous metal oxides possess unsaturated metal cations that function as Lewis acid sites while some crystal metal oxides such as heteropoly acids and layered metal oxides have Brønsted acid sites. Moreover, the acid strength can be controlled by choosing adequate component elements. Furthermore, the coexistence of Brønsted acid and Lewis acid sites can be realized on the surface of the oxide. These features have significant advantages for sugar conversions.

\section{Sugar Conversion}

The utilization of lignocellulosic biomass has attracted much attention because it is widely available, inedible and inexpensive. Lignocellulose consists of cellulose, hemicellulose and lignin. Cellulose is the most abundant natural biopolymer with rigid crystal structure which is composed of glucose units connected by the $\beta$-glycosidic bond along with the intramolecular hydrogen bond in three-dimensional fashion.

Figure 1 shows a representative scheme for the conversion of cellulose-based biomass toward useful chemicals. Depolymerization of cellulose to glucose or water-soluble oligomers is the first step for aqueous-phase sugar conversion. Glucose is a starting material for a variety of key intermediates. Isomerization of glucose gives fructose, while epimerization affords mannose. Dehydration of glucose forms anhydroglucose (levoglucosan) and levoglucosone. Fructose and levoglucosone are currently considered to be intermediate for HMF, which is obtained by dehydration of them.

Production of HMF is very important because it can be further transformed into 2,5-diformylfuran (DFF) and 2,5-furandicarboxylic acid (FDCA) via selective oxidation, which is the corresponding dialdehyde and dicarboxylic acid, respectively. The latter is particularly important because it can be an alternative to terephthalic acid from the viewpoint of the chemical structure. Thus FDCA has a high possibility as a precursor of biomass-based plastics, which will be widely used like polyethylene terephthalate (PET).

Glucose is classified as hexose (C6 sugar) and undergoes decomposition into trioses (C3 sugar), including glyceraldehyde and dihydroxyacetone via retroaldol condensation. These trioses are further converted into pyruvaldehyde, followed by lactic acid. Lactic acid is a precursor of polylactic acid which is a well-known biodegradable polymer.

The reduction of glucose gives sorbitol, which can be further converted into 1,4-sorbitan and isosorbide via cyclodehydration. Isosorbide is also an attractive precursor for synthesis of biomass-based polycarbonate, which has been commercialized.

For the conversion of cellulose-based biomass into value-added chemicals, many reactions are catalyzed by acid, including hydrolysis, dehydration, isomerization and retroaldol condensation. Here several types of metal oxide solid acids for sugar conversions will be introduced. 


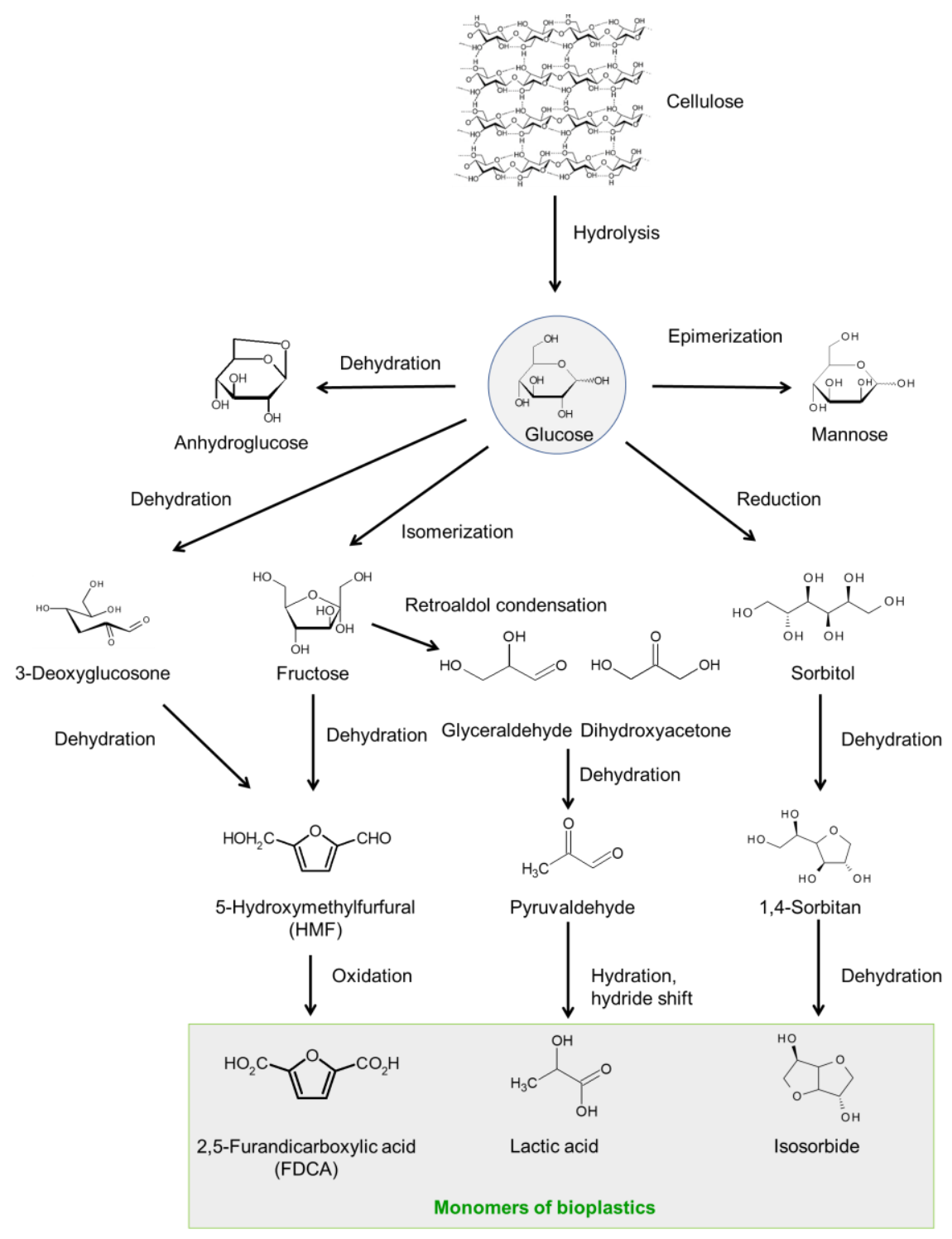

Figure 1. Reaction pathways for conversion of cellulose-based biomass toward chemicals.

\section{Layered Metal Oxides}

Protonated layered niobium molybdate and tantalum molybdate, $\mathrm{HNbMoO}_{6}$ and $\mathrm{HTaMoO}_{6}$, function as solid acid catalysts, whereas other layered metal oxides such as $\mathrm{HTiNbO}_{5}$ and $\mathrm{HNbWO}_{6}$ do not work because reactants cannot enter the interlayers [12-20]. The characteristics of layered $\mathrm{HNbMoO}_{6}$ and $\mathrm{HTaMoO}_{6}$ as solid acid catalysts are their unique ability of intercalation of reactants within the interlayers with strong Brønsted acid sites and high tolerance against water. The layered metal oxides consist of negatively charged $\left[\mathrm{NbMoO}_{6}\right]^{-}$or $\left[\mathrm{TaMoO}_{6}\right]^{-}$layers and positively charged $\mathrm{H}^{+}$. The proton between layers has strong Brønsted acidity, which is comparable to the strongest sites of H-ZSM5 zeolite [12,14]. A variety of reactants such as alcohols, aldehydes and hydroxy acids can be intercalated into the interlayers with strong acid sites, resulting in the high performance for acid-catalyzed reactions including Friedel-Crafts alkylation, acetalization, esterification, hydrolysis and hydration. The importance of intercalation for Friedel-Crafts alkylation of benzyl alcohol with anisole was confirmed by measurements of the interlayer distances of $\mathrm{HNbMoO}_{6}$ by X-ray diffraction (XRD) [12]. When the layered $\mathrm{HNbMoO}_{6}$ was immersed in benzyl alcohol solution, the interlayer distance of the layered $\mathrm{HNbMoO}_{6}$ increased due to the intercalation of the alcohol in which the total expansion was $0.55 \mathrm{~nm}$. The benzyl alcohol-intercalated $\mathrm{HNbMoO}_{6}$ could react with anisole 
at $373 \mathrm{~K}$ to produce the alkylated compounds. After the reaction, the interlayer distance decreased back. Moreover, the expansion of the interlayer distance was observed for the sample which was taken during the Friedel-Crafts alkylation. These results demonstrate that the interlayer sites of the layered oxide catalyst function as the active sites. The catalyst could apply for sugar conversion, including hydrolysis of sugars, cyclodehydration of sugar alcohols, epimerization of aldoses and mechanochemical decomposition of cellulose (Figure 2).

Selective intercalation

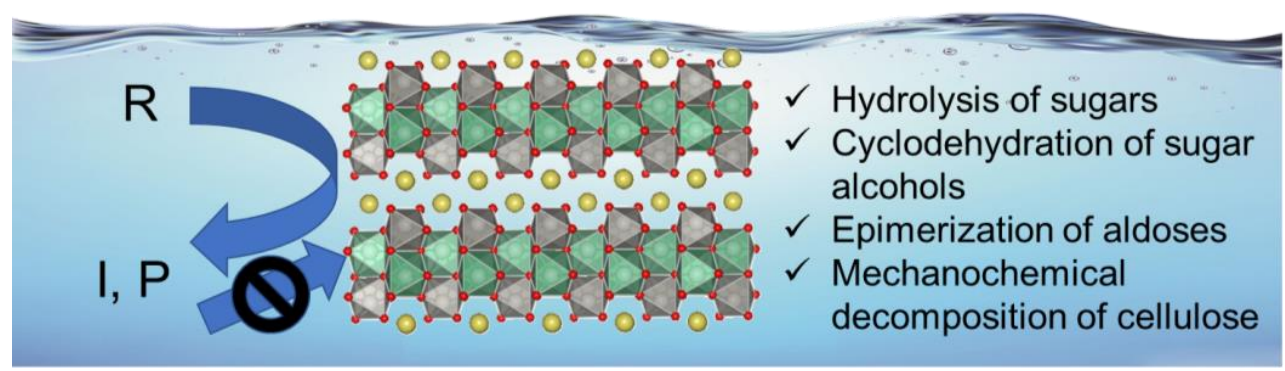

Figure 2. Sugar transformation in water using layered $\mathrm{HNbMoO}_{6}$ solid acid.

Since sugars and sugar alcohols have many hydroxyl groups, these compounds could be intercalated into the layered oxides and reacted with the acid sites of the layered oxides $[13,16,17]$. Disaccharides including cellobiose (a dimer of two glucose molecules connected by $\beta$-(1,4)-glycosidic bond) and sucrose (a dimer of glucose and fructose connected by $\alpha, \beta-(1,2)$-glycosidic bond) are water-soluble and able to be intercalated into the oxides, led to be hydrolyzed into corresponding monosaccharides. Figure 3 shows the results of the hydrolysis of sugars by using a variety of solid acids. The $\mathrm{HNbMoO}_{6}$ exhibited remarkable reaction rates and turnover frequencies. For sucrose hydrolysis, reaction rate of $\mathrm{HNbMoO}_{6}$ was ca. four times higher than that of Amberlyst- 15 catalyst. For cellobiose hydrolysis, turnover frequency of $\mathrm{HNbMoO}_{6}$ was ca. six times higher than that of Amberlyst-15. As mentioned above, H-type zeolites were difficult to use as Brønsted acid catalysts in water, resulting in negligible activity. Under these reaction conditions, no formation of glucose was observed in the absence of catalyst. The intercalation of sugars such as glucose, fructose, sucrose and cellobiose was confirmed by the expansion of the interlayer distance of the layered oxides.

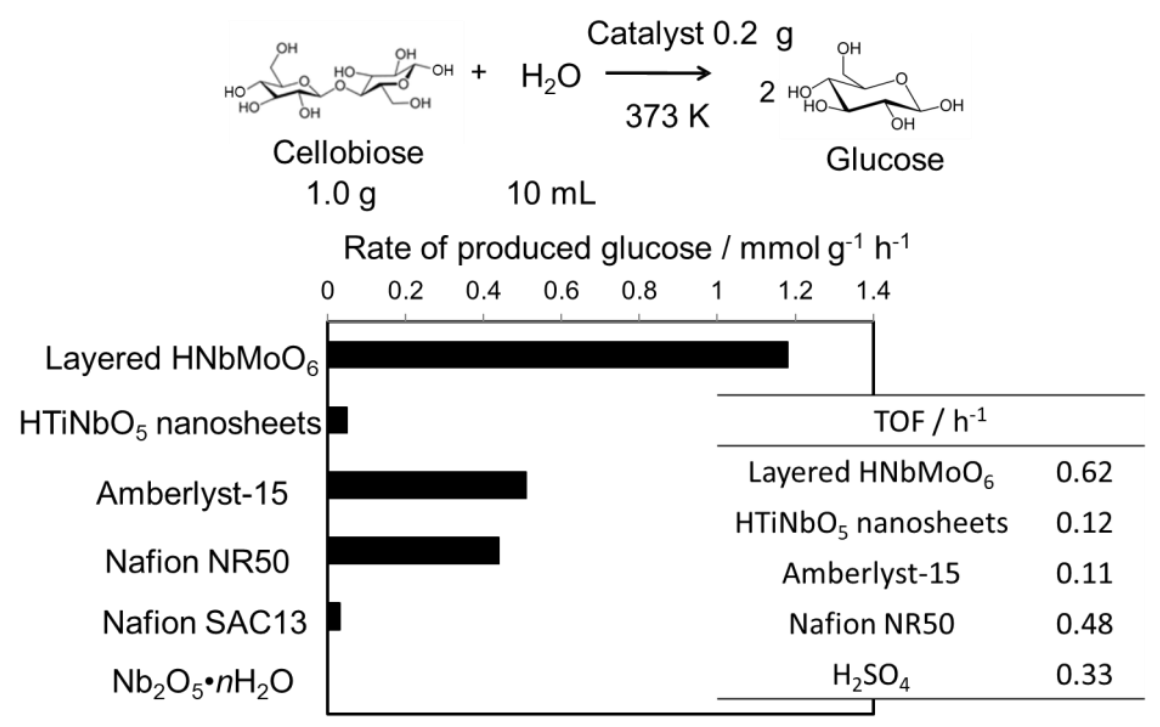

Figure 3. Hydrolysis of cellobiose over layered $\mathrm{HNbMoO}_{6}$ solid acid. 
Like sugars, sugar alcohols are also able to be intercalated into the $\mathrm{HNbMoO}_{6}$ catalyst. Sorbitol, sugar alcohol obtained by reduction of glucose, could be transformed into isosorbide by cyclodehydration. The transformation of sorbitol into isosorbide is a successive reaction via the formation of 1,4-sorbitol as an intermediate. Two consecutive 1,4-cyclodehydration reactions are necessary to afford isosorbide selectively. Other cyclodehydrations occur to form undesirable products such as 2,5-sorbitan and 1,5-sorbitan. Thus, the catalyst should highly recognize hydroxyl groups of sorbitol in order to obtain 1,4-sorbitan and isosorbide selectively. Water is a desirable solvent because it is so-called green solvent and monosaccharides were formed by aqueous-phase hydrolysis of oligomers. The $\mathrm{HNbMoO}_{6}$ catalyst could give 1,4-sorbitan from sorbitol in water [18]. The selectivity to 1,4 -sorbitan was $57 \%$ at the sorbitol conversion of $59 \%$. While the catalyst is not suitable for the production of isosorbide, which is useful for bio-based plastics, the high selectivity to 1,4-sorbitan is of significance from the viewpoint of fundamental chemistry because 1,4-sorbitan is an intermediate between two similar 1,4-cyclodehydration reactions. The selective formation of 1,4-sorbitan over $\mathrm{HNbMoO}_{6}$ was due to its selective intercalation. The layered $\mathrm{HNbMoO}_{6}$ was immersed in water containing sorbitol, 1,4-sorbitan or isosorbide, separately. After filtration and drying, XRD of the layered oxide was measured (Figure 4). The increase in the interlayer distance was found only for sorbitol. Thus, only sorbitol could be intercalated, whereas 1,4-sorbitan and isosorbide did not intercalate. Due to the selective intercalation, sorbitol could be converted into 1,4-sorbitan, but 1,4-sorbitan was difficult to make react with the acid sites of the layered oxide. Scheme 1 shows simplified reaction pathways for sorbitol cyclodehydration over $\mathrm{HNbMoO}_{6}$. Reaction rate constants of each reaction pathway were estimated by a kinetic study. The rate constant for the reaction from sorbitol to 1,4-sorbitan $\left(k_{1}\right)$ was two times higher than that for the reaction from 1,4-sorbitan to isosorbide $\left(k_{2}\right)$ over the $\mathrm{HNbMoO}_{6}$ catalyst. Besides, the preexponential factor for the first reaction is significantly higher than that for the second reaction. These results clearly show that the selective intercalation of reactants could control the successive reaction and produce an intermediate selectively.

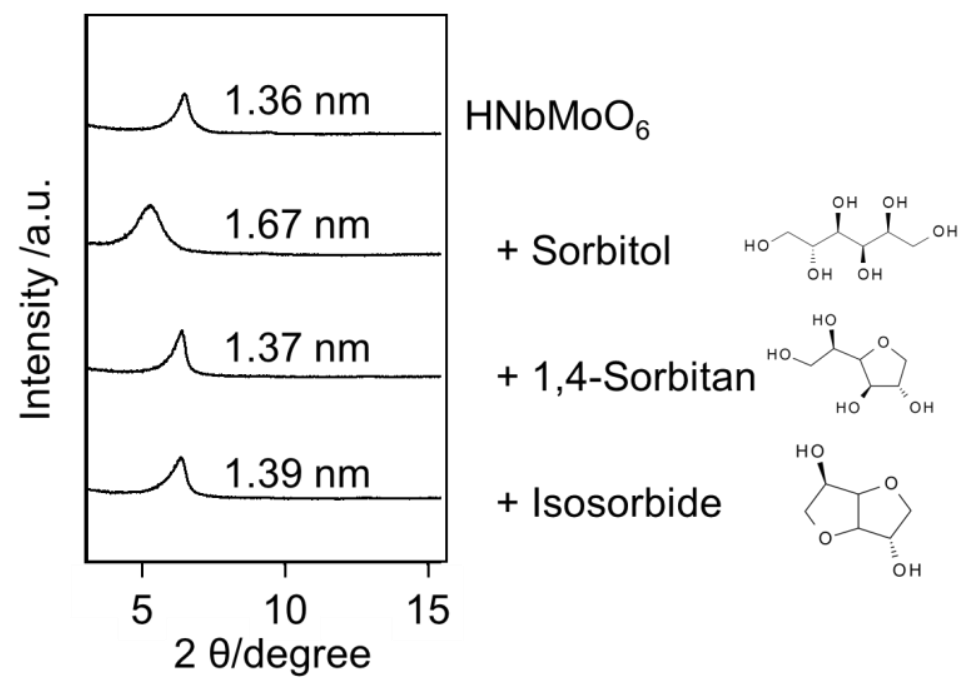

Figure 4. XRD patterns of $\mathrm{HNbMoO}_{6}$ after immersion in water involving sorbitol, 1,4-sorbitan or isosorbide. 


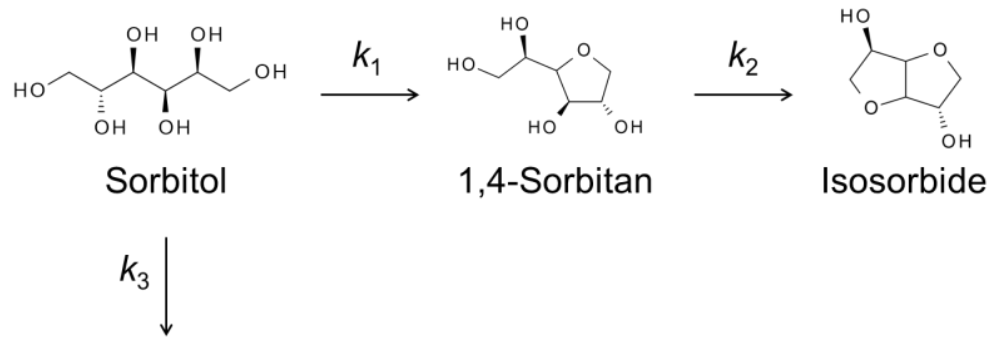

\section{Byproducts}

Scheme 1. Simplified reaction pathways for sorbitol cyclodehydration over layered $\mathrm{HNbMoO}_{6}$.

Like sorbitol, erythritol, C4 sugar alcohol could be dehydrated into 1,4-anhydroerythritol. Moreover, 1,4-butanediol was converted into tetrahydrofuran (THF) via the same 1,4-cyclodehydration. The $\mathrm{HNbMoO}_{6}$ catalyst exhibited moderate activity for 1,4-butanediol cyclodehydration, while it showed high activity for erythritol cyclodehydration [19]. Kinetic study on these cyclodehydration reactions over $\mathrm{HNbMoO}_{6}$ indicated that the difference of the activity between two $\mathrm{C} 4$ diols could be ascribed to different mobility of the activated complex based on the transition state theory. The pre-exponential factor after appropriate treatment is related to partition functions involving the contribution of 3D translation, 2D translation and 1D translation. The careful calculation indicated that the activated complex for 1,4-butanediol cyclodehydration is immobile, resulting in moderate activity (Figure 5). In contrast, the transition state for erythritol cyclodehydration is 2D translation, affording high activity. The ease of intercalation of reactants significantly affects the acid-catalyzed reaction.

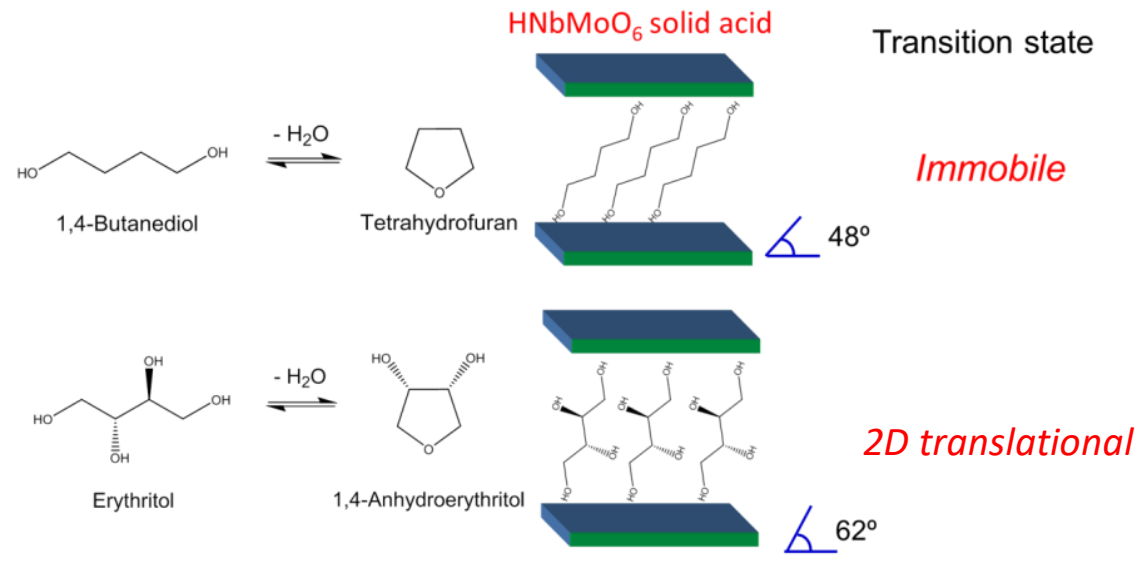

Figure 5. Intercalation-controlled cyclodehydrations of 1,4-butanediol and erythritol over layered $\mathrm{HNbMoO}_{6}$.

As described above, the intercalation of reactants within the interlayer with strong Brønsted acid sites is characteristic of the layered $\mathrm{HNbMoO}_{6}$. In other words, cellulose depolymerization over $\mathrm{HNbMoO}_{6}$ was difficult because cellulose is a big molecule and insoluble in water [13]. In these regards, the mechanochemical reaction as a different methodology was adopted for cellulose depolymerization [20]. It has been reported that ball-milling of crystalline cellulose in the presence of acidic kaolinite, a layered clay mineral could depolymerize it and the solid acidity of additives is important to accelerate the reaction [21]. The ball-milling of cellulose with layered $\mathrm{HNbMoO}_{6}$ could produce a high yield of water-soluble sugars (72\%) at full cellulose conversion without adding external heat, whereas the ball-milling of cellulose in the absence of catalyst afforded negligible yield of sugars $(<1 \%)$ [20]. Not only cello-oligomers such as cellobiose and cellotriose but also corresponding anhydro-sugars were produced by the mechanochemical reaction under dry conditions. The product distribution of water-soluble sugars showed that proportions of monosaccharides, disaccharides and 
other cello-oligomers from cellotriose to cellohexose were almost the same regardless of reaction time, whereas the total sugar yields monotonically increased (Figure 6). These results indicate that cellulose was randomly and directly decomposed into water-soluble sugars. The addition of a small amount of water improved the sugar yields and the selectivity of sugars/anhydrosugars was increased. The motion of balls was simulated by using a discrete element method (DEM) and then the mechanical energy was calculated. It was suggested that $0.02 \%$ of mechanical energy was applied for the cleavage of glycosidic bonds. Further improvement of the energy efficiency would be possible by scaling up the apparatus.

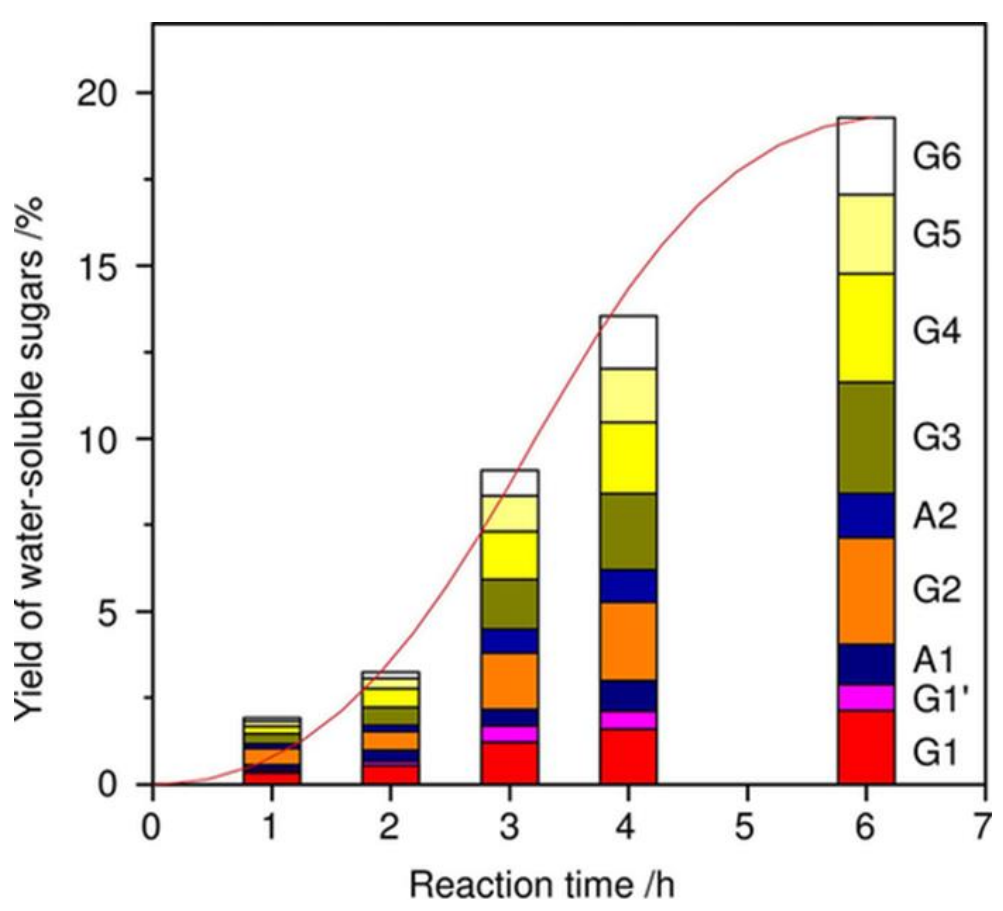

Figure 6. Dependence of yield of water-soluble sugars on reaction time (milling time). Reaction conditions: Microcrystalline cellulose (Avicel, $0.4 \mathrm{~g}$ ), layered $\mathrm{HNbMoO}_{6}(0.4 \mathrm{~g}), 600$ rpm. RT. G1: Glucose: G1': Mannose; G2: Cellobiose; G3: Cellotriose; G4: Cellotetraose; G5: Cellopentaose; G6: Cellohexaose; A1: Anhydroglucose; A2: Anhydrocellobiose. Reproduced with permission from [20]; copyright (2018), John Wiley \& Sons, Inc.

Another feature of the layered $\mathrm{NbMo}$ oxide is that it could efficiently catalyze the epimerization of aldoses [22]. Epimerization involves carbon-carbon rearrangement and is useful for the production of rare sugars. In the presence of $\mathrm{HNbMoO}_{6}$ or $\mathrm{LiNbMoO}_{6}$, glucose was quickly converted into mannose via epimerization (Figure 7). An ancient study demonstrated that $\mathrm{MoO}_{3}$ and homogeneous Mo complex could epimerize glucose to mannose, which was known as the Bilik reaction. Both $\mathrm{HNbMoO}_{6}$ and $\mathrm{LiNbMoO}_{6}$ could convert aldoses to the corresponding epimers (glucose to mannose, xylose to lyxose, arabinose to ribose) selectively. While $\mathrm{MoO}_{3}$ was completely dissolved in water during the reaction, these layered $\mathrm{NbMo}$ oxides were insoluble and could be reused without loss of activity. The active sites for the epimerization were considered to be the Mo octahedra at the surface, not the Mo octahedra within the interlayer. The turnover frequency for glucose epimerization over $\mathrm{LiNbMoO}_{6}$ was of significance, $1.1 \mathrm{~s}^{-1}$ at $393 \mathrm{~K}$, higher than that over Mo-based polyoxometalates. The combination of hydrolysis and epimerization over layered $\mathrm{HNbMoO}_{6}$ realized one-pot formation of mannose from cellobiose. Amberlyst-15, a representative Brønsted acid resin catalyst could hydrolyze cellobiose into glucose, but mannose was not formed. In contrast, $\mathrm{HNbMoO}_{6}$ also could hydrolyze cellobiose into glucose within the interlayer, and then mannose was obtained via epimerization. 
(A)

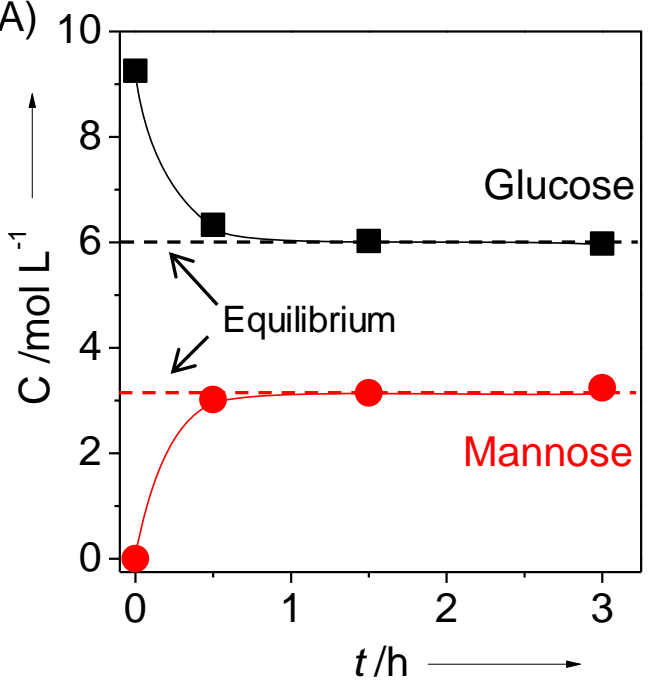

(B)

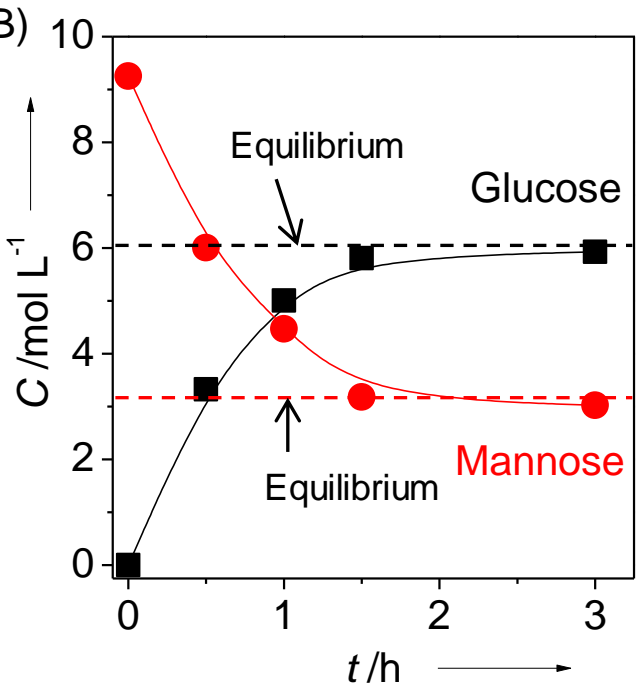

Figure 7. Time courses of epimerization of (a) glucose and (b) mannose over layered $\mathrm{LiNbMoO}_{6}$. Reaction conditions: Glucose (50 mg, $0.28 \mathrm{mmol})$, catalyst (50 mg), $\mathrm{H}_{2} \mathrm{O}(3 \mathrm{~mL}), 373 \mathrm{~K}$. Reproduced with permission from [22]; copyright (2015), John Wiley \& Sons, Inc.

\section{Metal Oxide Nanosheet Aggregates}

Protonated layered transition metal oxides have strong acid sites within the interlayer. However, most of the reactants cannot enter the interlayer spaces of these layered oxides except for $\mathrm{HNbMoO}_{6}$ and $\mathrm{HTaMoO}_{6}$. In order to overcome the drawbacks, a variety of protonated metal oxides, including $\mathrm{HTiNbO}_{5}, \mathrm{HTi}_{2} \mathrm{NbO}_{7}, \mathrm{HNb}_{3} \mathrm{O}_{8}, \mathrm{HNbWO}_{6}$ and $\mathrm{HTaWO}_{6}$ were utilized as solid acid catalysts by exfoliating them into the corresponding two-dimensional nanosheets [23-27]. Figure 8 shows the schematic crystal structure of metal oxide nanosheets. Figure 9 shows the preparation procedure of the metal oxide nanosheet aggregates. The addition of tetrabutylammonium hydroxide (TBAOH) into aqueous solution containing powder of protonated layered metal oxide could exfoliate the layered oxide because cationic $\mathrm{TBA}^{+}$can penetrate the interlayers by ion-exchange reaction and the bulky $\mathrm{TBA}^{+}$can peel the layered oxide down to the nanosheets. As a result, a colloidal solution containing exfoliated nanosheets was obtained in which exfoliated nanosheets were negatively charged and TBA cation surrounded the nanosheets. For the application of the nanosheets as solid acid catalysts, the exfoliated nanosheets should be solidified. The addition of $\mathrm{H}^{+}$, such as $\mathrm{HNO}_{3}, \mathrm{HCl}$ and $\mathrm{H}_{2} \mathrm{SO}_{4}$ collapsed the stability of the colloid, resulting in the rapid formation of nanosheet aggregates.

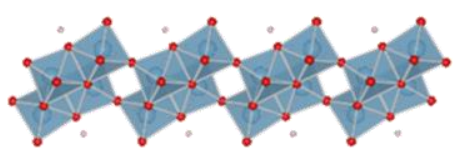

$\mathrm{HTiNbO}_{5}$

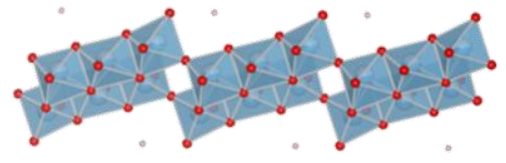

$\mathrm{HTi}_{2} \mathrm{NbO}_{7}$

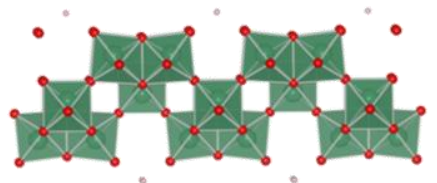

$\mathrm{HNb}_{3} \mathrm{O}_{8}$

Figure 8. Schematic crystal structure of metal oxide nanosheets. 


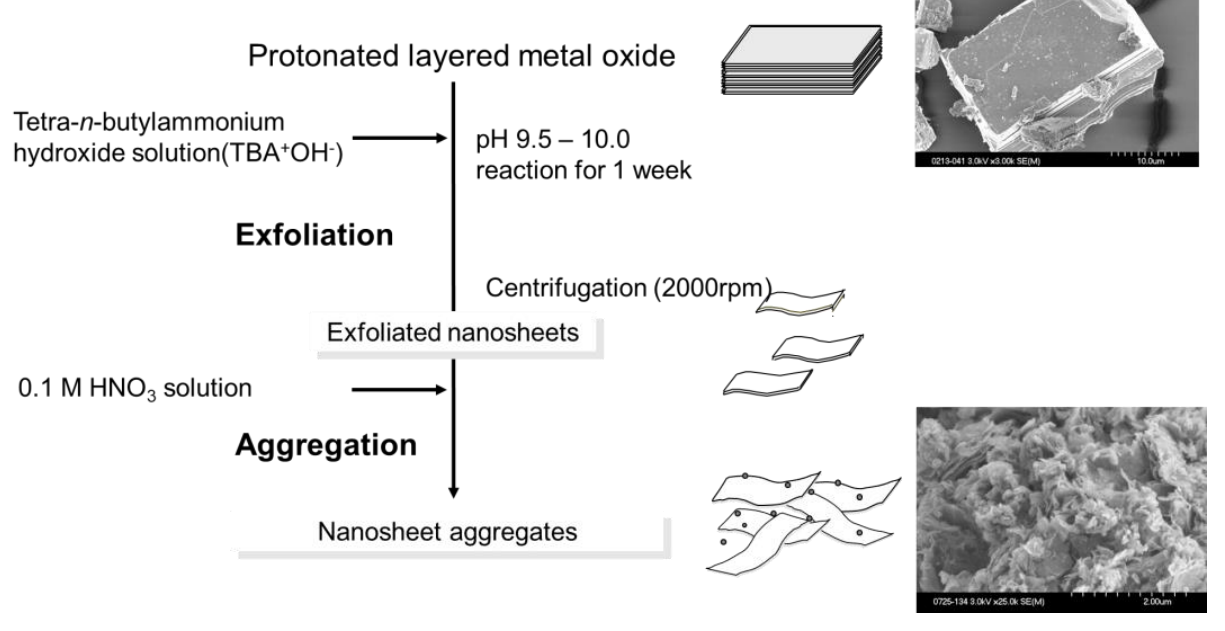

Figure 9. The preparation procedure of metal oxide nanosheet aggregates.

The nanosheet aggregates had large surface areas and had Brønsted acid sites because proton was on the surface as counter ions. The solid acid properties of the nanosheet aggregates were evaluated by solid-state nuclear magnetic resonance (NMR) spectroscopy and temperature-programmed desorption of ammonia ( $\left.\mathrm{NH}_{3}-\mathrm{TPD}\right)$. $\mathrm{NH}_{3}$-TPD is a conventional method to estimate acid strength and acid amounts of solids. However, careful consideration is required when the method was applied for the metal oxide nanosheet aggregates because the nanosheet aggregates may change their crystal structures while raising temperature. Trimethylphosphine oxide (TMPO) was widely used as a probe molecule of ${ }^{31} \mathrm{P}$ magic angle spinning (MAS) NMR for investigating Brønsted acid strength [28]. The interaction of TMPO with Brønsted acid sites of the solid catalyst gives protonated TMPO $\left(\mathrm{TMPOH}^{+}\right)$. This species shows ${ }^{31} \mathrm{P}$ chemical shifts at higher ppm than crystalline TMPO. Thus, the chemical shifts of TMPO adsorbed correspond to the acid strength of solid acids. The ${ }^{31} \mathrm{P}$ MAS NMR measurements using TMPO as a probe molecule indicated that the acid strength of transition metal oxide nanosheet aggregates dramatically depends on the constituent element compositions, in the order of $\mathrm{HTiNbO}_{5}<$ $\mathrm{HNb}_{3} \mathrm{O}_{8}<\mathrm{HNbWO}_{6}<\mathrm{HTaWO}_{6}$ (Figure 10) [26].

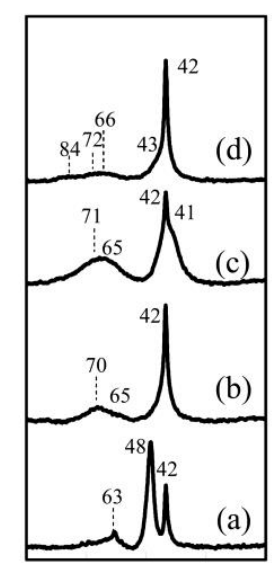

$\begin{array}{lllll}100 & 75 & 50 & 25 & 0\end{array}$ $\delta / \mathbf{p p m}$

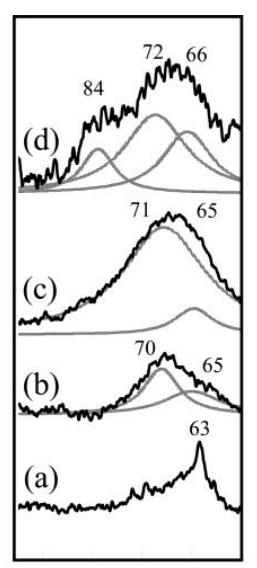

$95 \quad 85 \quad 75 \quad 65 \quad 55$

$\delta / \mathbf{p p m}$

Figure 10. ${ }^{31} \mathrm{P}$ magic angle spinning (MAS) NMR spectra for trimethylphosphine oxide (TMPO) adsorbed (a) $\mathrm{HTiNbO}_{5}$ nanosheets aggregate, (b) $\mathrm{HNb}_{3} \mathrm{O}_{8}$ nanosheets aggregate, (c) $\mathrm{HNbWO}_{6}$ nanosheets aggregate and (d) $\mathrm{HTaWO}_{6}$ nanosheets aggregate, measured at room temperature. The spinning rate of the sample was $10 \mathrm{kHz}$. Reproduced with permission from [26]; copyright (2009), American Chemical Society. 
These nanosheet aggregates have so far been applied for hydrolysis of disaccharides [13], furfural formation from xylose [29] and $\mathrm{HMF}$ formation from fructose and glucose [30,31]. $\mathrm{HTiNbO}_{5}$ nanosheets had a high surface areas of ca. $150 \mathrm{~m}^{2} \mathrm{~g}^{-1}$ with an acid amount of $0.4 \mathrm{mmol} \mathrm{g}^{-1}$ and exhibited the catalytic activity for hydrolysis of sucrose, higher turnover frequency than Nafion NR50, Amberlyst-15, $\mathrm{Nb}_{2} \mathrm{O}_{5} n \mathrm{H}_{2} \mathrm{O}, \mathrm{H}-\mathrm{ZSM} 5$ and liquid $\mathrm{H}_{2} \mathrm{SO}_{4}$. The acid strength of $\mathrm{HTiNbO}_{5}$ nanosheets was moderate, resulting in low activity for hydrolysis of cellobiose, which needs strong acids for cleavage of the 1,4- $\beta$-glycosidic bond (Figure 3) [13].

A variety of metal oxide nanosheet aggregates, including $\mathrm{HTiNbO}_{5}, \mathrm{HTi}_{2} \mathrm{NbO}_{7}, \mathrm{H}_{2} \mathrm{Ti}_{3} \mathrm{O}_{7}, \mathrm{HNb}_{3} \mathrm{O}_{8}$ and $\mathrm{H}_{4} \mathrm{Nb}_{6} \mathrm{O}_{17}$, were tested for furfural formation from xylose in water-toluene biphasic solution at $433 \mathrm{~K}$ [29]. A high furfural yield of $55 \%$ with a xylose conversion of $92 \%$ was obtained over $\mathrm{HTiNbO}_{5}$ nanosheet aggregates, which were prepared by addition of $\mathrm{MgO}$ during the aggregation process. There was a correlation between the initial catalytic activities of the nanosheet aggregates and the total amount of Brønsted and Lewis acid sites. These titanoniobate nanosheet aggregates were reusable for the reaction (Figure 11).

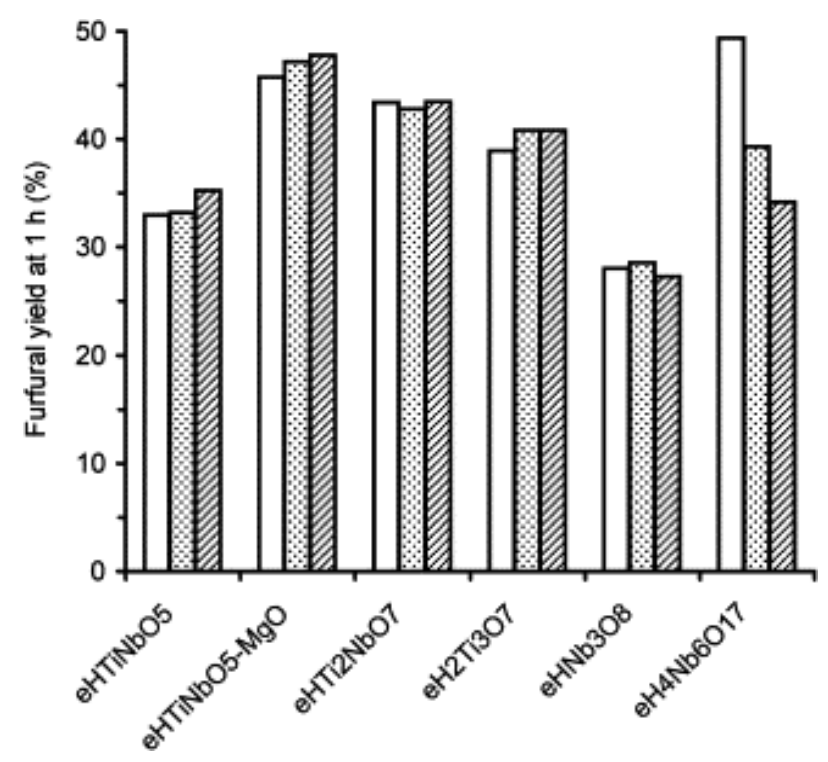

Figure 11. Furfural yield obtained in recycling runs (run 1-white bar, run 2-dots, run 3-hashed) over the exfoliated-aggregated nanosheet solid acid catalysts. Reproduced with permission from [29]; copyright (2006), Elsevier.

$\mathrm{HMF}$ formation from fructose and glucose in water was demonstrated using layered $\mathrm{HNb}_{3} \mathrm{O}_{8}$ under microwave irradiation [30]. The layered $\mathrm{HNb}_{3} \mathrm{O}_{8}$ was exfoliated during the reaction with fructose under microwave irradiation, affording $\mathrm{HMF}$ yield of $56 \%$ at $423 \mathrm{~K}$. The exfoliated $\mathrm{HNb}_{3} \mathrm{O}_{8}$ nanosheets were restacked after the reaction. Thus the catalyst showed reusability.

Very recently, it was reported that three acidic nanosheet aggregates, including $\mathrm{HTiNbO}_{5}, \mathrm{HNb}_{3} \mathrm{O}_{8}$ and $\mathrm{HNbWO}_{6}$ were applied for aqueous-phase glucose conversion to HMF [31]. The activity was in the order of $\mathrm{HTiNbO}_{5}<\mathrm{HNb}_{3} \mathrm{O}_{8}<\mathrm{HNbWO}_{6}$, which is in good agreement with the order of their acidity. $\mathrm{HNbWO}_{6}$ nanosheet aggregates exhibited high $\mathrm{HMF}$ selectivity of $52 \%$ with glucose conversion of $71 \%$ in a water-toluene biphasic system. It should be noted that the formation of HMF from glucose was higher than that from fructose over $\mathrm{HNbWO}_{6}$ nanosheet aggregates. A kinetic study suggested that not only fructose but also another intermediate, possibly 3-deoxyglucosone, was involved in the reaction (Scheme 2). When 3-deoxyglucosone and fructose were used as reactants, the selectivity to HMF from 3-deoxyglucosone was much higher than that from fructose. 


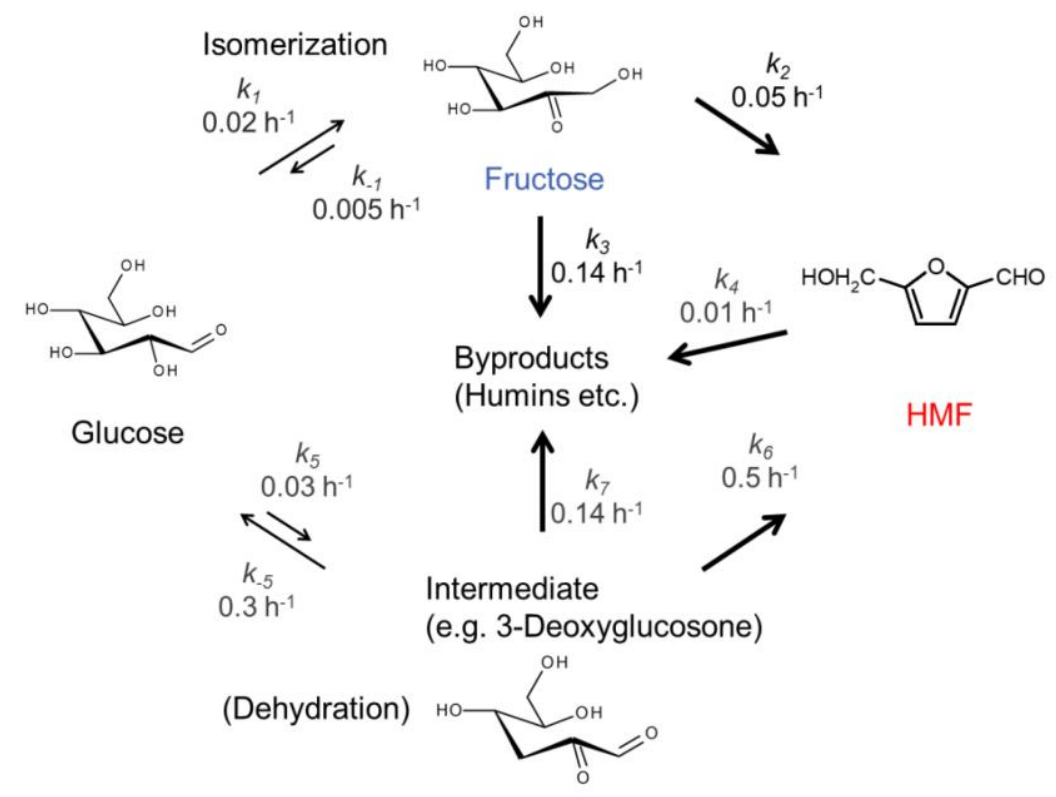

Scheme 2. Proposed reaction pathway for $\mathrm{HMF}$ production over $\mathrm{HNbWO}_{6}$ aggregated nanosheets. Reproduced with permission from [31].

\section{Metal Oxide Nanotubes}

Titanium oxide nanotubes are readily prepared by hydrothermal synthesis. The titanate nanotubes had high surface areas $\left(400 \mathrm{~m}^{2} \mathrm{~g}^{-1}\right)$ with both Brønsted and Lewis acid sites [32,33]. The nanotubes showed excellent activity for Friedel-Crafts alkylation of toluene with benzylchloride. Even at room temperature, the catalyst could give $92 \%$ yield of the corresponding product, which was much higher than $\mathrm{H} \beta$ zeolite, sulfated zirconia and ion-exchange resins, including Nafion and Amberlyst. Besides, the titanate nanotubes afforded HMF from glucose and fructose. However, the HMF yield was moderate (ca. $14 \%$ ) from glucose at $393 \mathrm{~K}$.

\section{Mesoporous Metal Oxides}

Mesoporous $\mathrm{Nb}-\mathrm{W}$ mixed oxides catalyzed not only Friedel-Crafts alkylation but also hydrolysis of disaccharides [34]. The mesoporous metal oxides were prepared from metal chlorides and a poly-block copolymer surfactant Pluronic P-123 as a structure-directing agent. Figure 12 shows SEM and TEM images of mesoporous $\mathrm{Nb}-\mathrm{W}$ mixed oxides. The mesoporous structure was formed for $\mathrm{Nb}_{2} \mathrm{~W}_{8}$ to $\mathrm{Nb}$ oxides. The surface areas were $132 \mathrm{~m}^{2} \mathrm{~g}^{-1}$ for mesoporous $\mathrm{Nb}_{3} \mathrm{~W}_{7}$ oxide, $166 \mathrm{~m}^{2} \mathrm{~g}^{-1}$ for $\mathrm{Nb}_{5} \mathrm{~W}_{5}$ oxide and $193 \mathrm{~m}^{2} \mathrm{~g}^{-1}$ for $\mathrm{Nb}$ oxide. The catalytic activity for Friedel-Crafts alkylation of anisole with benzyl alcohol and hydrolysis of sucrose was significantly influenced by the $\mathrm{Nb}$ and $\mathrm{W}$ contents. The mesoporous $\mathrm{Nb}$ oxide with the highest surface areas and pore volume among them showed negligible activity. Increasing tungsten content accelerated the reaction rate, reaching the highest yield mesoporous $\mathrm{Nb}_{3} \mathrm{~W}_{7}$ oxide. Further increase of tungsten content drastically decreased the activity due to the collapse of the mesoporosity. The catalytic activity for these two reactions was related to the Brønsted acidity. ${ }^{31} \mathrm{P}$ MAS NMR using TMPO indicated that mesoporous $\mathrm{Nb}-\mathrm{W}$ oxide had strong Brønsted acid sites in the range of $-12 \leq H_{0}<-6.6$ in which $\mathrm{Nb}_{3} \mathrm{~W}_{7}$ oxide had the strongest Brønsted acid sites among them. Figure 13 shows the comparison of the catalytic activity for sucrose hydrolysis by using several solid acid catalysts. Non-porous $\mathrm{Nb}_{3} \mathrm{~W}_{7}$ oxide which was prepared in the absence of the structure-directing agent showed higher activity than two ion-exchange resins (Amberlyst-15 and Nafion NR50) and niobic acid. Mesoporous $\mathrm{Nb}_{3} \mathrm{~W}_{7}$ oxide displayed much higher activity than non-porous $\mathrm{Nb}_{3} \mathrm{~W}_{7}$ oxide. The mesoporous $\mathrm{Nb}_{3} \mathrm{~W}_{7}$ oxide also efficiently accelerated cellobiose hydrolysis. The rate of glucose formation at $368 \mathrm{~K}$ was $0.42 \mathrm{mmol} \mathrm{g}^{-1} \mathrm{~h}^{-1}$ for mesoporous 
$\mathrm{Nb}_{3} \mathrm{~W}_{7}$ oxide, two times higher than that of Amberlyst-15 $\left(0.22 \mathrm{mmol} \mathrm{g}^{-1} \mathrm{~h}^{-1}\right)$. The turnover frequency of mesoporous $\mathrm{Nb}_{3} \mathrm{~W}_{7}$ oxide was $1.40 \mathrm{~h}^{-1}, 28$ times higher than that of Amberlyst- $15\left(0.05 \mathrm{~h}^{-1}\right)$.

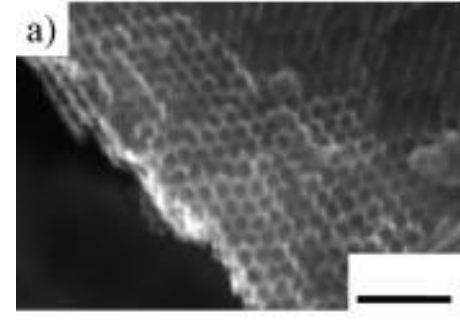

d)

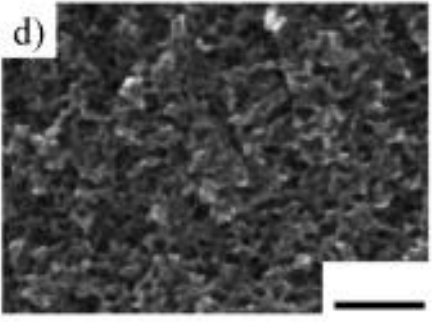

g)

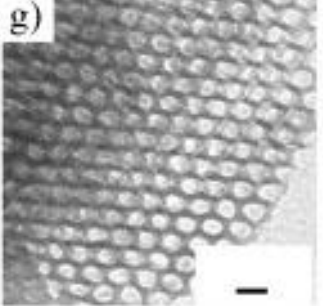

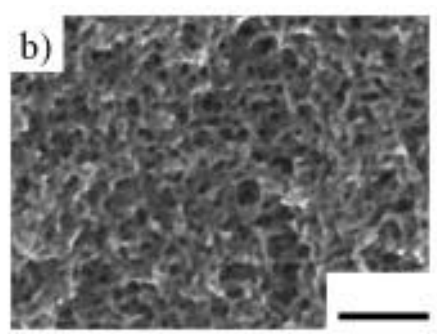
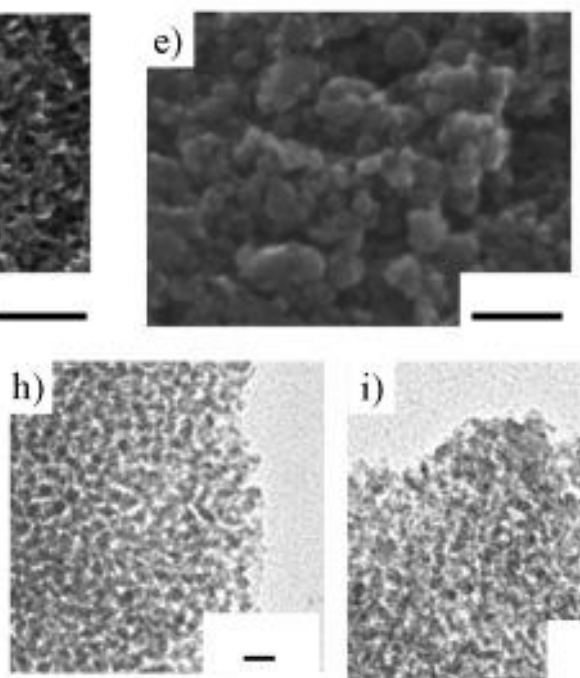

i)
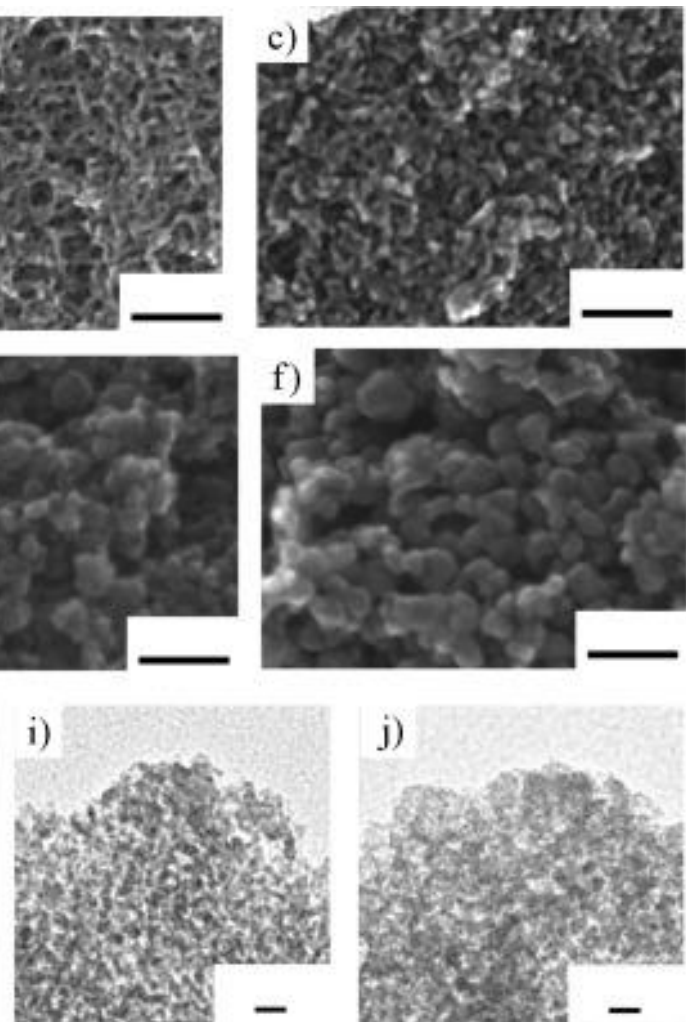

j)

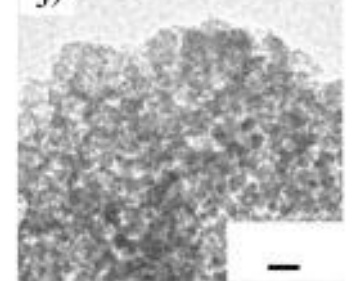

Figure 12. SEM images of mesoporous (a) $\mathrm{Nb}$, (b) $\mathrm{Nb}_{7} \mathrm{~W}_{3}$, (c) $\mathrm{Nb}_{5} \mathrm{~W}_{5}$ and (d) $\mathrm{Nb}_{3} \mathrm{~W}_{7}$ oxides (scale bar: $50 \mathrm{~nm}$ ). SEM images of non-mesoporous (e) $\mathrm{Nb}_{1} \mathrm{~W}_{9}$ and (f) $\mathrm{W}$ oxides (scale bar: $50 \mathrm{~nm}$ ). TEM images of mesoporous (g) Nb, (h) $\mathrm{Nb}_{7} \mathrm{~W}_{3}$, (i) $\mathrm{Nb}_{5} \mathrm{~W}_{5}$ and (j) $\mathrm{Nb}_{3} \mathrm{~W}_{7}$ oxides (scale bar: $10 \mathrm{~nm}$ ). Reproduced with permission from [34]; copyright (2010), John Wiley \& Sons, Inc.

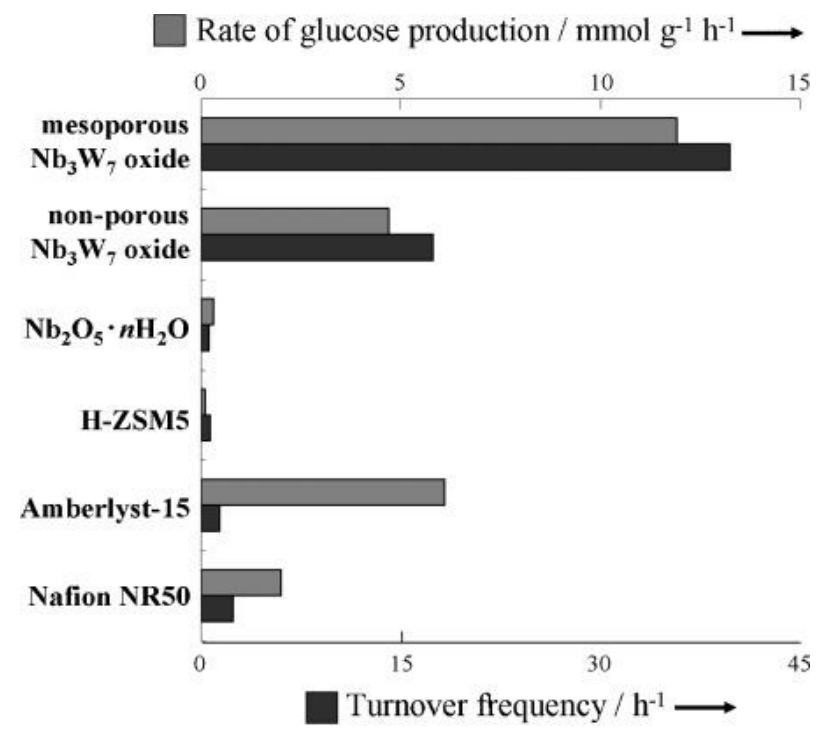

Figure 13. Hydrolysis of sucrose over several solid acid catalysts. Reaction conditions: Sucrose (0.5 g, $1.46 \mathrm{mmol}), \mathrm{H}_{2} \mathrm{O}(10 \mathrm{~mL}, 556 \mathrm{mmol})$, catalyst $(0.1 \mathrm{~g}), 353 \mathrm{~K} 1 \mathrm{~h}$. Reproduced with permission from [34]; copyright (2010), John Wiley \& Sons, Inc. 
Like $\mathrm{Nb}-\mathrm{W}$ oxides, mesoporous $\mathrm{Ta}-\mathrm{W}$ oxides were synthesized and applied for solid acid catalysts [35]. Again, mesoporous $\mathrm{Ta}_{3} \mathrm{~W}_{7}$ oxide exhibited the highest activity for Friedel-Crafts alkylation and hydrolysis of disaccharides among various $\mathrm{Ta}_{\mathrm{x}}-\mathrm{W}_{1-\mathrm{x}}$ oxides.

Niobic acid $\left(\mathrm{Nb}_{2} \mathrm{O}_{5} \cdot n \mathrm{H}_{2} \mathrm{O}\right)$ is known as a water-tolerant solid acid catalyst $[7,8]$. The use of amphiphilic block copolymers as structure-directing agents gave mesoporous $\mathrm{Nb}_{2} \mathrm{O}_{5} \cdot n \mathrm{H}_{2} \mathrm{O}$ [36] . The mesoporous structures such as surface areas, pore volumes and pore size distributions could be controlled by using different amphiphilic block copolymers, L64, P85, P103 and P123. Figure 14 shows the glucose formation from cellobiose via hydrolysis using mesoporous $\mathrm{Nb}_{2} \mathrm{O}_{5} \cdot n \mathrm{H}_{2} \mathrm{O}$, bulk $\mathrm{Nb}_{2} \mathrm{O}_{5} \cdot n \mathrm{H}_{2} \mathrm{O}$ and ion-exchange resins. Mesoporous $\mathrm{Nb}_{2} \mathrm{O}_{5} \cdot n \mathrm{H}_{2} \mathrm{O}$ prepared with $\mathrm{P} 103\left(\mathrm{~S}_{\mathrm{BET}} 246 \mathrm{~m}^{2} \mathrm{~g}^{-1}\right.$ ) (Figure 14(Ac)) and P123 (S $\mathrm{SET}_{\mathrm{BET}} 343 \mathrm{~m}^{2} \mathrm{~g}^{-1}$ ) (Figure 14(Ad)) exhibited excellent activity for the reaction. Moreover, the turnover frequency for mesoporous $\mathrm{Nb}_{2} \mathrm{O}_{5} \cdot n \mathrm{H}_{2} \mathrm{O}$ prepared with $\mathrm{P} 103$ was much higher than that for bulk $\mathrm{Nb}_{2} \mathrm{O}_{5} \cdot n \mathrm{H}_{2} \mathrm{O}\left(\mathrm{S}_{\mathrm{BET}} 171 \mathrm{~m}^{2} \mathrm{~g}^{-1}\right)$. Because of no significant difference in solid acid property among the porous and bulk $\mathrm{Nb}_{2} \mathrm{O}_{5} \cdot n \mathrm{H}_{2} \mathrm{O}$, porous structure would facilitate the diffusion of reactant and product.
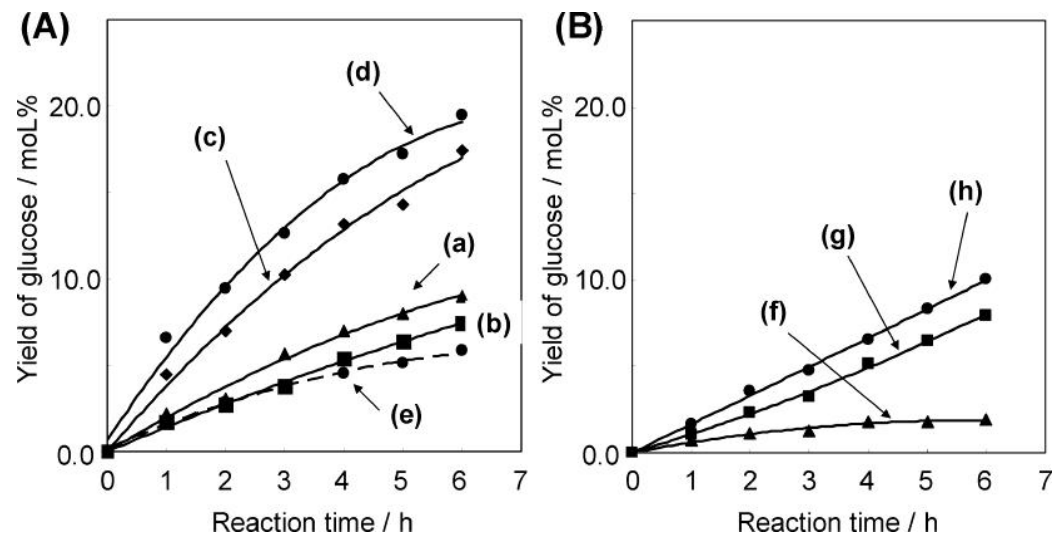

Figure 14. Time courses for d-glucose formation by the hydrolysis of cellobiose over (A) bulk and supermicroporous/mesoporous $\mathrm{Nb}_{2} \mathrm{O}_{5} \cdot n \mathrm{H}_{2} \mathrm{O}$ and (B) strongly acidic resin. (a) Mesoporous $\mathrm{Nb}_{2} \mathrm{O}_{5} \cdot n \mathrm{H}_{2} \mathrm{O}$ prepared with $\mathrm{L} 64$, (b) supermicroporous $\mathrm{Nb}_{2} \mathrm{O}_{5} \cdot n \mathrm{H}_{2} \mathrm{O}$ prepared with $\mathrm{P} 85$, (c) mesoporous $\mathrm{Nb}_{2} \mathrm{O}_{5} \cdot n \mathrm{H}_{2} \mathrm{O}$ prepared with P103, (d) mesoporous $\mathrm{Nb}_{2} \mathrm{O}_{5} \cdot n \mathrm{H}_{2} \mathrm{O}$ prepared with P123, (e) bulk $\mathrm{Nb}_{2} \mathrm{O}_{5} \cdot n \mathrm{H}_{2} \mathrm{O}$, (f) Nafion-silica (SAC-13), (g) Nafion resin (NR-50) and (h) Amberlyst-15. Reproduced with permission from [36]; copyright (2010), American Chemical Society.

Mesoporous tantalum oxide was applied for HMF formation from glucose [37]. The synthesized mesoporous $\mathrm{Ta}_{2} \mathrm{O}_{5} \cdot 0.19 \mathrm{H}_{2} \mathrm{O}$ had the BET surface areas of $79 \mathrm{~m}^{2} \mathrm{~g}^{-1}$ and total acid sites of $353 \mu \mathrm{mol} \mathrm{g} \mathrm{g}^{-1}$. The mesoporous tantalum oxide had both Brønsted acid and Lewis acid sites, which could contribute to the formation of HMF from glucose. HMF yield of $23 \%$ and glucose conversion of $69 \%$ were obtained in a biphasic water/methyl isobutyl ketone (MIBK) system at $448 \mathrm{~K}$.

\section{Amorphous Metal Oxides}

Amorphous metal oxides could have both Brønsted and Lewis acid sites on the surface. The former is generally attributed to hydroxyl groups $(-\mathrm{OH})$ and the latter is derived from coordinatively unsaturated metal sites (:M). There was a great contribution to aqueous sugar conversion by using amorphous metal oxides in which Lewis acid sites were applicable for the reactions even in water. Niobic acid, $\mathrm{Nb}_{2} \mathrm{O}_{5} \cdot n \mathrm{H}_{2} \mathrm{O}$ is a hydrated amorphous niobium oxide and has been considered as a water-tolerant Brønsted acid catalyst so far [3]. However, it was disclosed that the Lewis acid sites of niobic acid could work even in water [38]. Raman and FTIR measurements revealed that $\mathrm{NbO}_{4}$ tetrahedra of niobic acid function as Lewis acid sites even in the presence of water. In Raman spectroscopy, the vibrational band at $988 \mathrm{~cm}^{-1}$ attributed to $\mathrm{NbO}_{4}$ tetrahedra was observed for dehydrated $\mathrm{Nb}_{2} \mathrm{O}_{5} \cdot n \mathrm{H}_{2} \mathrm{O}$. After exposure to water vapor, this band at $988 \mathrm{~cm}^{-1}$ disappeared, indicating 
the formation of $\mathrm{NbO}_{4}-\mathrm{H}_{2} \mathrm{O}$ adducts. The band was recovered after heating at $423 \mathrm{~K}$ to remove the water. It was claimed that the reversibility was not reported in isolated $\mathrm{NbO}_{4}$ species on other oxide surfaces. Figure 15 shows FTIR spectra for CO-adsorbed $\mathrm{Nb}_{2} \mathrm{O}_{5} \cdot n \mathrm{H}_{2} \mathrm{O}$. The three bands at 2188,2168 and $2145 \mathrm{~cm}^{-1}$ were ascribed to $\mathrm{CO}$ adsorbed on Lewis acid sites, on Brønsted acid sites and physisorbed $\mathrm{CO}$, respectively [39]. It was observed that the hydrated $\mathrm{Nb}_{2} \mathrm{O}_{5} \cdot n \mathrm{H}_{2} \mathrm{O}$, which had $3 \mathrm{mmol}$ of water adsorbed on $1 \mathrm{~g}$ of the metal oxide, still had Lewis acid sites (Figure 15B), though most of the $\mathrm{NbO}_{4}$ tetrahedra was converted into $\mathrm{NbO}_{4} \cdot \mathrm{H}_{2} \mathrm{O}$ adducts. The water-tolerant Lewis acid sites on $\mathrm{Nb}_{2} \mathrm{O}_{5} \cdot n \mathrm{H}_{2} \mathrm{O}$ could catalyze the allylation of benzaldehyde with tetraallyl tin in water and selective conversion of glucose into HMF in water. Table 1 shows the HMF formation from glucose using $\mathrm{Nb}_{2} \mathrm{O}_{5} \cdot n \mathrm{H}_{2} \mathrm{O}, \mathrm{Na}^{+}$-treated $\mathrm{Nb}_{2} \mathrm{O}_{5} \cdot n \mathrm{H}_{2} \mathrm{O}$ and $\mathrm{H}_{3} \mathrm{PO}_{4}$-treated $\mathrm{Nb}_{2} \mathrm{O}_{5} \cdot n \mathrm{H}_{2} \mathrm{O}$ in water. The three non-treated and treated $\mathrm{Nb}_{2} \mathrm{O}_{5} \cdot n \mathrm{H}_{2} \mathrm{O}$ could produce $\mathrm{HMF}$ from glucose, whereas other solid acids such as ion-exchange resins and $\mathrm{H}$-type zeolites could not. The treatment with $\mathrm{Na}^{+}$was effective in diminishing the Brønsted acid sites. The HMF selectivity of $\mathrm{Na}$-treated $\mathrm{Nb}_{2} \mathrm{O}_{5} \cdot n \mathrm{H}_{2} \mathrm{O}$ remained unchanged, indicating that Lewis acid sites catalyze the reaction. The treatment with $\mathrm{H}_{3} \mathrm{PO}_{4}$ could block neutral $\mathrm{OH}$ groups on the surface, resulting in high selectivity to HMF (52\%) due to suppression of side reactions to form unknown species.
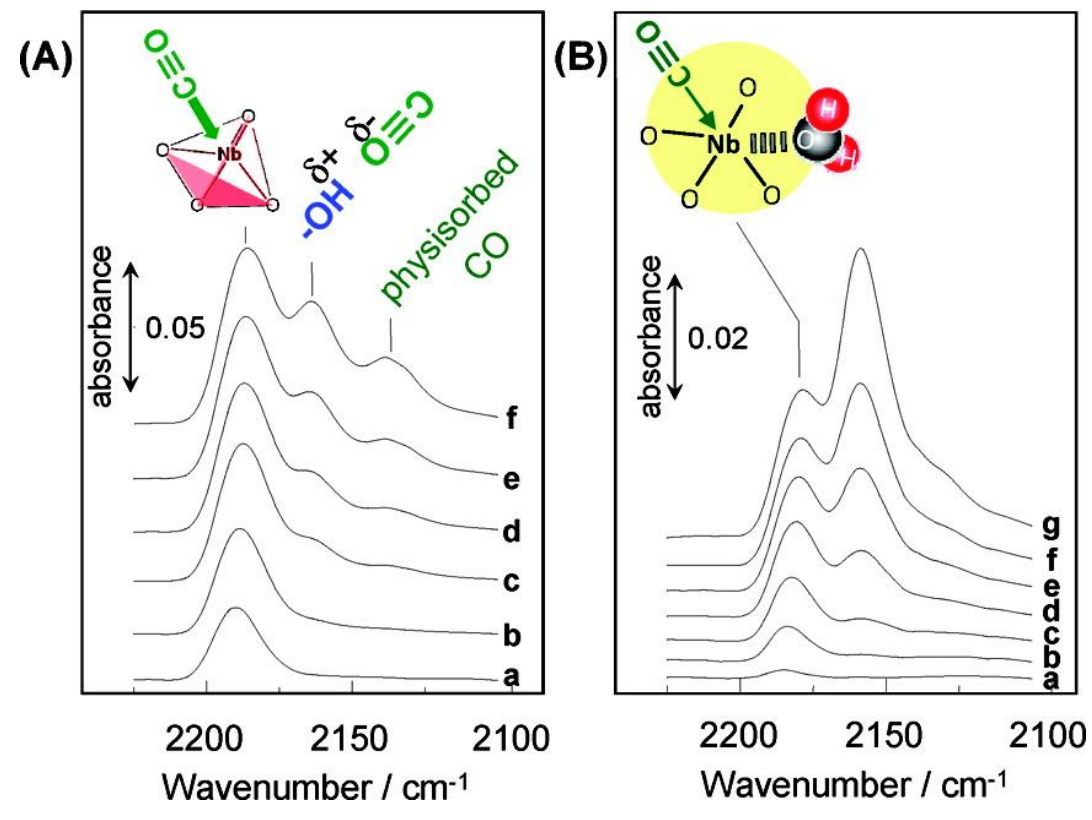

Figure 15. Differential FT-IR spectra for (A) dehydrated and (B) hydrated $\mathrm{Nb}_{2} \mathrm{O}_{5} \cdot n \mathrm{H}_{2} \mathrm{O}$ at $90 \mathrm{~K}$. (A) Prior to $\mathrm{CO}$ adsorption, the sample was heated at $423 \mathrm{~K}$ for $1 \mathrm{~h}$ under vacuum. Gas phase $\mathrm{CO}$ pressure: (a) $7.1 \times 10^{-3}$, (b) $1.2 \times 10^{-2}$, (c) $2.2 \times 10^{-2}$, (d) $4.0 \times 10^{-2}$, (e) $6.6 \times 10^{-2}$ and (f) $1.4 \times 10^{-1}$ $\mathrm{kPa}$. Prior to $\mathrm{CO}$ adsorption, the sample was dehydrated at room temperature for $24 \mathrm{~h}$ under vacuum. Gas-phase CO pressure: (a) $6.1 \times 10^{-3}$, (b) $9.3 \times 10^{-3}$, (c) $1.4 \times 10^{-2}$, (d) $2.6 \times 10^{-2}$, (e) $4.3 \times 10^{-2}$, (f) $6.8 \times 10^{-2}$ and (g) $1.4 \times 10^{-1} \mathrm{kPa}$. Reproduced with permission from [38]; copyright (2011), American Chemical Society. 
Table 1. Catalytic activity for the conversion of glucose into HMF in water a Reproduced with permission from [38]; copyright (2011), American Chemical Society.

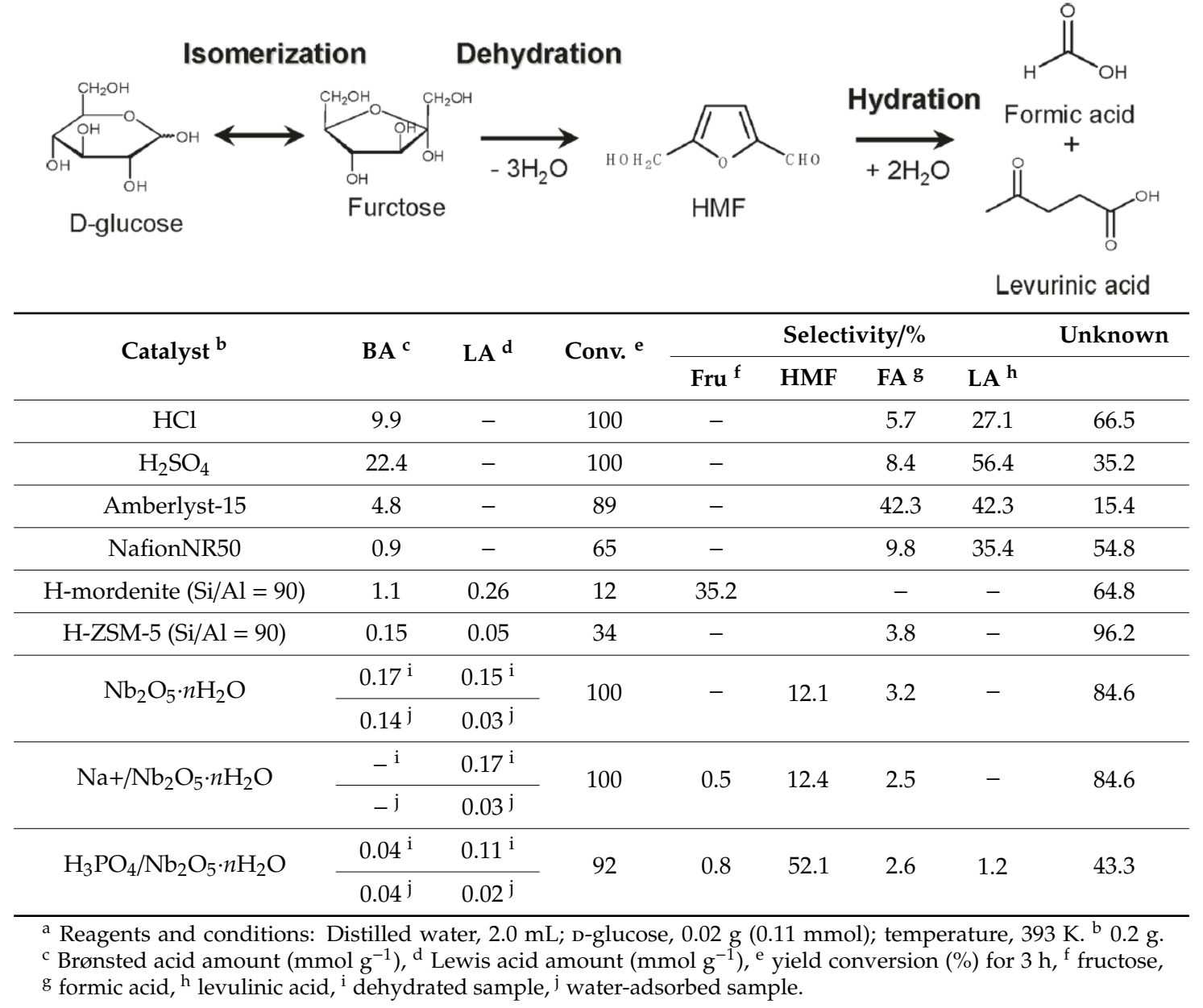

Different from the above study, the treatment of niobic acid with phosphoric acid and subsequent calcination was known to be effective for improving the catalytic activity of niobic acid [40]. The $\mathrm{H}_{3} \mathrm{PO}_{4}$-treated niobic acid calcined at $573 \mathrm{~K}$ was used for HMF formation from various sugars, including fructose, glucose, inulin and the Jerusalem artichoke juice [41]. At $433 \mathrm{~K}$ in a biphasic water-2-butanol system, HMF yield was $89 \%$ from fructose, $49 \%$ from glucose and $54 \%$ from inulin, respectively.

Anatase with low crystallinity was also workable as a water-tolerant Lewis acid catalyst [42]. The $\mathrm{TiO}_{2}$ had a high density of Lewis acid sites, $\mathrm{TiO}_{4}$ tetrahedra, which could survive in water, resulting in higher catalytic activity for pyruvaldehyde conversion to lactic acid. The $\mathrm{TiO}_{2}$ and $\mathrm{H}_{3} \mathrm{PO}_{4}$-treated $\mathrm{TiO}_{2}$ (phosphate/ $\mathrm{TiO}_{2}$ ) also could produce HMF from glucose in water [43]. It should be noted that the reaction mechanism on the $\mathrm{TiO}_{2}$ catalyst was different from other solid Lewis acid catalysts such as Sn-Beta zeolite [43,44]. There are two possible reaction mechanisms for HMF formation from glucose. One involves glucose-fructose isomerization and subsequent dehydration. Fructose is an intermediate and an appropriate combination of Lewis acid and Brønsted acid is required. The other mechanism proceeds via stepwise dehydration where 3-deoxyglucosone (3, 3-Deoxy-2-ketohexose) is considered as an intermediate (Figure 16) [45]. Experiments using isotopically labeled molecules and solid-state NMR and a theoretical study revealed that $\mathrm{TiO}_{2}$ and phosphate/ $/ \mathrm{TiO}_{2}$ followed the stepwise dehydration mechanism (Figure 17). 


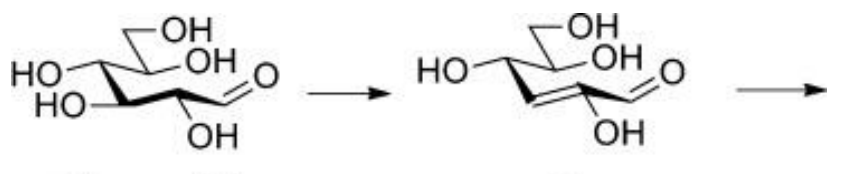

Glucose (1) 2

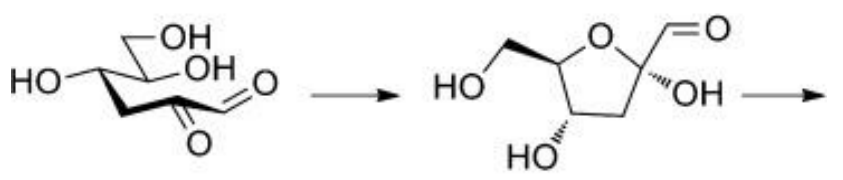

3

4

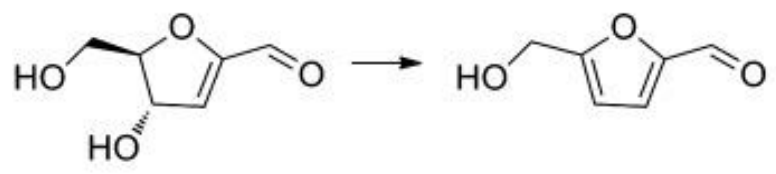

5

$\operatorname{HMF}(6)$

Figure 16. The 3-Deoxy-2-ketohexose mechanism for formation of HMF. Reproduced with permission from [45]; copyright (2011), John Wiley \& Sons, Inc.

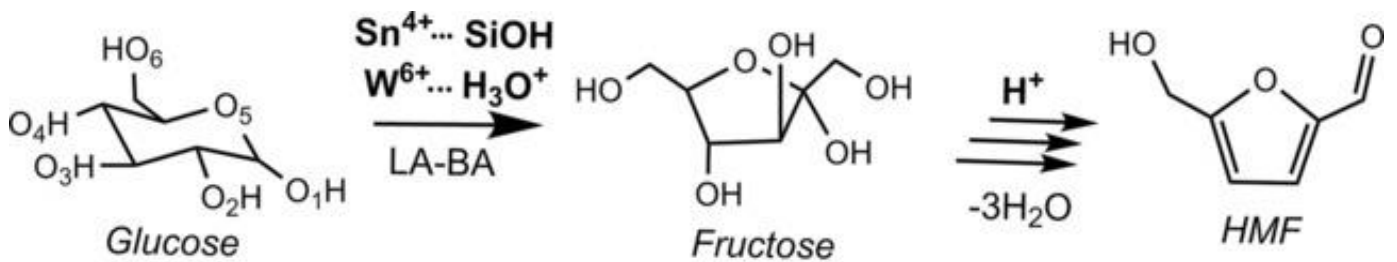

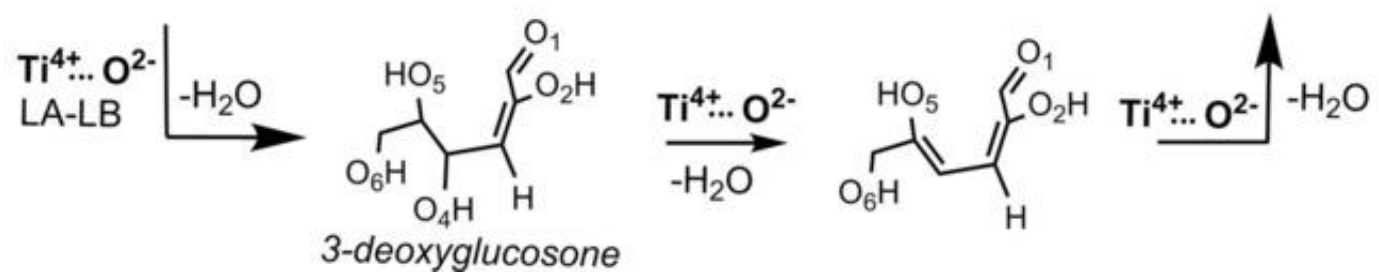

Figure 17. Two synergetic strategies converting glucose to HMF: (i) Glucose isomerization by cooperation between a Lewis acid and a proton donor (example systems are $\mathrm{Sn} / \mathrm{Beta}$ and $\mathrm{WO}_{3} \cdot \mathrm{H}_{2} \mathrm{O}$ ) followed by fructose dehydration and (ii) stepwise glucose dehydration catalyzed by a Lewis acid-base pair (an example being Ti4c-O-Ti-OH on titania). Reproduced with permission from [44]; copyright (2018), John Wiley \& Sons, Inc.

\section{Supported Metal Oxides}

Supported catalysts are widely used for the chemical industry. The use of supports with high surface areas enables high dispersion of active species. The high atomic efficiency is preferable for the guideline of green chemistry.

A variety of silica-supported metal oxides were investigated for lactic acid formation from trioses in water [46]. It was found that silica-supported chromia-titania catalysts selectively afforded lactic acid ( $80 \%$ yield) at $403 \mathrm{~K}$. The co-impregnation of chromium oxide and titanium oxide formed both Brønsted acid and Lewis acid sites on the surface. There was a trend in the Lewis/Brønsted acid ratio to the selectivity to lactic acid (Figure 18). Scheme 3 shows the reaction pathway for lactic acid formation from trioses in water. Table 2 shows reaction rate constants for each reaction pathway over using silica-supported titania, chromia and chromia-titania catalysts. The $\mathrm{Cr} / \mathrm{SiO}_{2}$ catalyst with Lewis acid sites was effective at converting pyruvaldehyde to lactic acid, indicating a high rate constant of $k_{\mathrm{L}}$. 
The $\mathrm{Ti} / \mathrm{SiO}_{2}$ catalyst with Brønsted acid sites could promote the reaction from dihydroxyacetone to pyruvaldehyde, which led to a high rate constant of $k_{\mathrm{p}}$. The $\mathrm{Cr}-\mathrm{Ti} / \mathrm{SiO}_{2}$ catalyst could increase these two essential rate constants, $k_{\mathrm{L}}$ and $k_{\mathrm{p}}$, which gave the high reaction rate with high selectivity to lactic acid. The supported metal oxides could easily control their acid properties including acid amounts, acid types and the Brønsted/Lewis acid ratio by changing the loading amount and metal compositions.

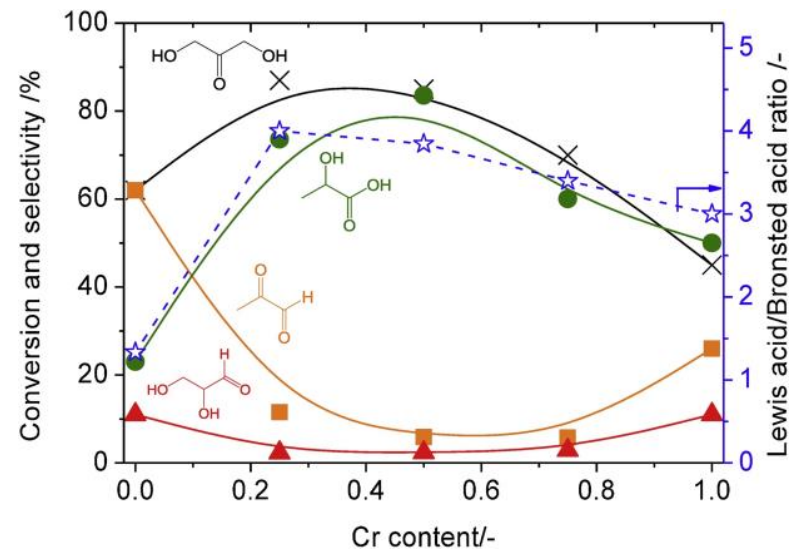

Figure 18. Conversion of dihydroxyaceonte (DHA), selectivity of products and Lewis acid/Brønsted acid ratios as a function of chromium contents in silica-supported chromium-titanium mixed oxides. Reaction conditions: Dihydroxyacetone $(0.55 \mathrm{mmol})$, catalyst $(50 \mathrm{mg})$, water $(3 \mathrm{~mL}), 130{ }^{\circ} \mathrm{C}, 1.5 \mathrm{~h}$. Reproduced with permission from [46]; copyright (2019), Elsevier.

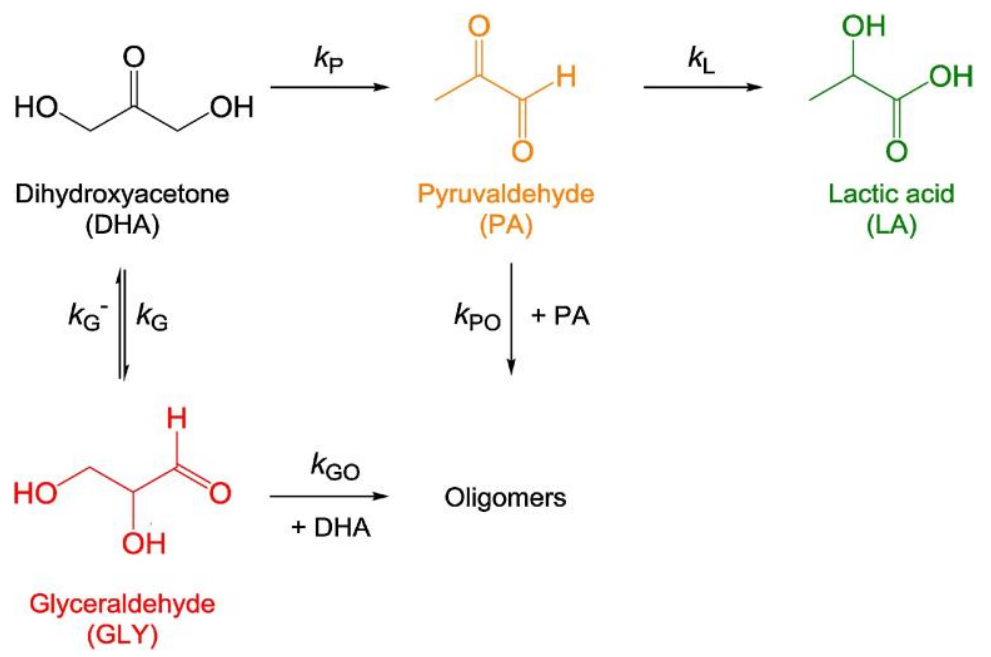

Scheme 3. Proposed reaction pathway for dihydroxyacetone transformation. Reproduced with permission from [46]; copyright (2019), Elsevier.

Table 2. Rate constants for dihydroxyacetone (DHA) transformation using silica-supported chromium oxide, titanium oxide and chromium-titanium oxide catalysts (units in $\mathrm{h}^{-1}$ ). Reproduced with permission from [46]; copyright (2019), Elsevier.

\begin{tabular}{ccccccc}
\hline & $k_{\mathrm{p}}$ & $k_{\mathrm{L}}$ & $k_{\mathrm{G}}$ & $k_{\mathrm{G}^{-}}$ & $k_{\mathrm{GO}}$ & $k_{\mathrm{PO}}$ \\
\hline $\mathrm{Cr}(1.0) / \mathrm{SiO}_{2}$ & 0.36 & 1.8 & 0.3 & 3.8 & 4.8 & 36 \\
$\mathrm{Ti}(1.0) / \mathrm{SiO}_{2}$ & 0.6 & 0.24 & 0.18 & 1.1 & 6 & 1.2 \\
$\mathrm{Cr}(0.5)-\mathrm{Ti}(0.5) / \mathrm{SiO}_{2}$ & 1.2 & 3 & 0.12 & 1.2 & 3 & 30 \\
\hline
\end{tabular}




\section{Conclusions}

From glucose as a key chemical building block, a variety of intermediates could be synthesized by several acid-catalyzed reactions. Some metal oxides could function as water-tolerant solid acids and be applicable for these reactions. The textural properties such as crystal structure, morphology and porosity greatly affected the amounts and types of acid sites and the diffusivity of reactants. Layeredand mesoporous structures were effective for improving the product selectivity and for enhancing the reaction rate, respectively. The solid acids with strong Brønsted acid sites such as layered $\mathrm{HNbMoO}_{6}$ and mesoporous $\mathrm{Nb}-\mathrm{W}$ oxides could catalyze hydrolysis and (cyclo)dehydration. The solid acids with Lewis acid sites such as amorphous niobium oxide and anatase could promote HMF formation. A combination of Brønsted and Lewis acid was effective for lactic acid synthesis. Not only tuning of Brønsted and Lewis acidity but also improving accessibility of the reactant with the active sites is a key for the selective formation of the desired product.

Funding: This work was supported by JSPS KAKENHI Grant Number JP 25709077 and 18 H01785.

Conflicts of Interest: The authors declare no conflict of interest.

\section{References}

1. Capello, C.; Fischer, U.; Hungerbühler, K. What is a green solvent? A comprehensive framework for the environmental assessment of solvents. Green Chem. 2007, 9, 927-934. [CrossRef]

2. Ravenelle, R.M.; Coperland, J.R.; Kim, W.-G.; Crittenden, J.C.; Sievers, C. Structural Changes of $\gamma-\mathrm{Al}_{2} \mathrm{O}_{3}$-Supported Catalysts in Hot Liquid Water. ACS Catal. 2011, 1, 552-561. [CrossRef]

3. Okuhara, T. Water-Tolerant Solid Acid Catalysts. Chem. Rev. 2002, 102, 3641-3666. [CrossRef] [PubMed]

4. Namba, S.; Hosonuma, Y.; Yashima, T. Catalytic application of hydrophobic properties of high-silica zeolites. I. Hydrolysis of ethyl acetate in aqueous solution. J. Catal. 1981, 72, 16-20. [CrossRef]

5. Ishida, H. Liquid-phase hydration process of cyclohexene with zeolites. Catal. Surv. Jpn. 1997, 1, 241-246. [CrossRef]

6. Kimura, M.; Nakato, T.; Okuhara, T. Water-tolerant solid acid catalysis of $\mathrm{Cs}_{2.5} \mathrm{H}_{0.5} \mathrm{PW}_{12} \mathrm{O}_{40}$ for hydrolysis of esters in the presence of excess water. Appl. Catal. A Gen. 1997, 165, 227-240. [CrossRef]

7. Tanabe, K.; Okazaki, S. Various reactions catalyzed by niobium compounds and materials. Appl. Catal. A Gen. 1995, 133, 191-218. [CrossRef]

8. Nowak, I.; Ziolek, M. Niobium Compounds: Preparation, Characterization, and Application in Heterogeneous Catalysis. Chem. Rev. 1999, 99, 3603-3624. [CrossRef]

9. Li, K.; Yoshinaga, Y.; Okuhara, T. Water-tolerant catalysis by Mo-Zr mixed oxides calcined at high temperatures. Phys. Chem. Chem. Phys. 1999, 1, 4913-4918. [CrossRef]

10. Armaroli, T.; Busca, C.; Carlini, C.; Giuttari, M.; Raspolli, G.; Anna, M.; Sbrana, G. Acid site characterization of niobium phosphate catalysts and their activity in fructose dehydration to 5-hydroxymethyl-2-furaldehyde. J. Mol. Catal. A Chem. 2000, 151, 233-243. [CrossRef]

11. Okuhara, T. New catalytic functions of heteropoly compounds as solid acids. Catal. Today 2002, 73, 167-176. [CrossRef]

12. Tagusagawa, C.; Takagaki, A.; Hayashi, S.; Domen, K. Efficient Utilization of Nanospace of Layered Transition Metal Oxide $\mathrm{HNbMoO}_{6}$ as a Strong, Water-Tolerant Solid Acid Catalyst. J. Am. Chem. Soc. 2008, 130, 7230-7231. [CrossRef]

13. Takagaki, A.; Tagusagawa, C.; Domen, K. Glucose production from saccharides using layered transition metal oxide and exfoliated nanosheets as a water-tolerant solid acid catalyst. Chem. Commun. 2008, 42, 5363-5365. [CrossRef] [PubMed]

14. Tagusagawa, C.; Takagaki, A.; Hayashi, S.; Domen, K. Evaluation of strong acid properties of layered $\mathrm{HNbMoO}_{6}$ and catalytic activity for Friedel-Crafts alkylation. Catal. Today 2009, 142, 267-271. [CrossRef]

15. Takagaki, A.; Sasaki, R.; Tagusagawa, C.; Domen, K. Intercalation-induced Esterification over a Layered Transition Metal Oxide. Top. Catal. 2009, 52, 592-596. [CrossRef] 
16. Tagusagawa, C.; Takagaki, A.; Takanabe, K.; Ebitani, K.; Hayashi, S.; Domen, K. Effects of Transition-metal Composition of Protonated Layered Non-Stoichiometric Oxides $\mathrm{H}_{1-\mathrm{x}} \mathrm{Nb}_{1-\mathrm{x}} \mathrm{Mo}_{1+\mathrm{x}} \mathrm{O}_{6}$ on Heterogeneous Acid Catalysis. J. Phys. Chem. C 2009, 113, 17421-17427. [CrossRef]

17. Tagusagawa, C.; Takagaki, A.; Takanabe, K.; Ebitani, K.; Hayashi, S.; Domen, K. Layered and nanosheets tantalum molybdate as solid acid catalysts. J. Catal. 2010, 270, 206-212. [CrossRef]

18. Morita, Y.; Furusato, S.; Takagaki, A.; Hayashi, S.; Kikuchi, R.; Oyama, S.T. Intercalation-Controlled Cyclodehydration of Sorbitol in Water over Layered-Niobium-Molybdate Solid Acid. ChemSusChem 2014, 7, 748-752. [CrossRef]

19. Takagaki, A. Kinetic analysis of aqueous-phase cyclodehydration of 1,4-butanediol and erythritol over a layered niobium molybdate solid acid. Catal. Sci. Technol. 2016, 6, 791-799. [CrossRef]

20. Furusato, S.; Takagaki, A.; Hayashi, S.; Miyazato, A.; Kikuchi, R.; Oyama, S.T. Mechanochemical Decomposition of Crystalline Cellulose in the Presence of Protonated Layered Niobium Molybdate Solid Acid Catalyst. ChemSusChem 2018, 11, 888-896. [CrossRef]

21. Hick, S.M.; Griebel, C.; Restrepo, D.T.; Truitt, J.H.; Buker, E.J.; Bylda, C.; Blair, R.G. Mechanocatalysis for biomass-derived chemicals and fuels. Green Chem. 2010, 12, 468-474. [CrossRef]

22. Takagaki, A.; Furusato, S.; Kikuchi, R.; Oyama, S.T. Efficient Epimerization of Aldoses Using Layered Niobium Molybdates. ChemSusChem 2015, 8, 3769-3772. [CrossRef]

23. Takagaki, A.; Sugisawa, M.; Lu, D.; Kondo, J.N.; Hara, M.; Domen, K.; Hayashi, S. Exfoliated Nanosheets as a New Strong Solid Acid Catalyst. J. Am. Chem. Soc. 2003, 125, 5479-5485. [CrossRef]

24. Takagaki, A.; Yoshida, T.; Lu, D.; Kondo, J.N.; Hara, M.; Domen, K.; Hayashi, S. Titanium Niobate and Titanium Tantalate Nanosheets as Strong Solid Acid Catalysts. J. Phys. Chem. B 2004, 108, 11549-11555. [CrossRef]

25. Takagaki, A.; Lu, D.; Kondo, J.N.; Hara, M.; Hayashi, S.; Domen, K. Exfoliated $\mathrm{HNb}_{3} \mathrm{O}_{8}$ Nanosheets as Strong Protonic Solid Acid. Chem. Mater. 2005, 17, 2487-2489. [CrossRef]

26. Tagusagawa, C.; Takagaki, A.; Hayashi, S.; Domen, K. Characterization of $\mathrm{HNbWO}_{6}$ and $\mathrm{HTaWO}_{6}$ metal oxide nanosheet aggregates as solid acid catalysts. J. Phys. Chem. C 2009, 113, 7831-7837. [CrossRef]

27. Takagaki, A.; Tagusagawa, C.; Hayashi, S.; Hara, M.; Domen, K. Nanosheets as highly active solid acid catalysts for green chemical syntheses. Energy Environ. Sci. 2010, 3, 82-93. [CrossRef]

28. Zheng, A.; Liu, S.-B.; Deng, F. ${ }^{31}$ P NMR Chemical Shifts of Phosphorous Probes as Reliable and Practical Acidity Scales for Solid and Liquid Catalysts. Chem. Rev. 2017, 117, 12475-12531. [CrossRef]

29. Dias, A.S.; Kima, S.; Carriazo, D.; Rives, V.; Pillinger, M.; Valente, A.A. Exfoliated titanate, niobate and titanoniobate nanosheets as solid acid catalysts for the liquid-phase dehydration of D-xylose into furfural. J. Catal. 2006, 244, 230-237. [CrossRef]

30. Wu, Q.; Yan, Y.; Zhang, Q.; Lu, J.; Yang, Z.; Zhang, Y.; Tang, Y. Catalytic Dehydration of Carbohydrates on In Situ Exfoliatable Layered Niobic Acid in an Aqueous System under Microwave Irradiation. ChemSusChem 2013, 6, 820-825. [CrossRef]

31. Takagaki, A. Production of 5-Hydroxymethylfurfural from Glucose in Water by Using Transition Metal-Oxide Nanosheet Aggregates. Catalysts 2019, 9, 818. [CrossRef]

32. Kitano, M.; Nakajima, K.; Kondo, J.N.; Hayashi, S.; Hara, M. Protonated Titanate Nanotube as Solid Acid Catalyst. J. Am. Chem. Soc. 2010, 132, 6622-6623. [CrossRef]

33. Kitano, M.; Wada, E.; Nakajima, K.; Hayashi, S.; Miyazaki, S.; Kobayashi, H.; Hara, M. Protonated Titanate Nanotubes with Lewis and Brønsted Acidity: Relationship between Nanotube Structure and Catalytic Activity. Chem. Mater. 2013, 25, 385-393. [CrossRef]

34. Tagusagawa, C.; Takagaki, A.; Iguchi, A.; Takanabe, K.; Kondo, J.N.; Ebitani, K.; Hayashi, S.; Tatsumi, T.; Domen, K. Highly Active Mesoporous Nb-W Oxide Solid-Acid Catalyst. Angew. Chem. Int. Ed. 2010, 49, 1128-1132. [CrossRef]

35. Tagusagawa, C.; Takagaki, A.; Iguchi, A.; Takanabe, K.; Kondo, J.N.; Ebitani, K.; Tatsumi, T.; Domen, K. Synthesis and Characterization of Mesoporous Ta-W Oxides as Strong Solid Acid Catalysts. Chem. Mater. 2010, 22, 3072-3078. [CrossRef]

36. Nakajima, K.; Fukui, T.; Kato, H.; Kitano, M.; Kondo, J.N.; Hayashi, S.; Hara, M. Structure and Acid Catalysis of Mesoporous $\mathrm{Nb}_{2} \mathrm{O}_{5} \cdot n \mathrm{H}_{2} \mathrm{O}$. Chem. Mater. 2010, 22, 3332-3339. [CrossRef] 
37. Jiménez-Morales, I.; Moreno-Recio, M.; Santamaría-González, J.; Maireles-Torres, P.; Jiménez-López, A. Mesoporous tantalum oxide as catalyst for dehydration of glucose to 5-hydroxymethylfurfural. Appl. Catal. B Environ. 2014, 154-155, 190-196. [CrossRef]

38. Nakajima, K.; Baba, Y.; Noma, R.; Kitano, M.; Kondo, J.N.; Hayashi, S.; Hara, M. $\mathrm{Nb}_{2} \mathrm{O}_{5} \cdot \mathrm{nH}_{2} \mathrm{O}$ as a Heterogeneous Catalyst with Water-Tolerant Lewis Acid Sites. J. Am. Chem. Soc. 2011, 133, 4224-4227. [CrossRef]

39. Busca, G. The surface acidity of solid oxides and its characterization by IR spectroscopic methods. An attempt at systematization. Phys. Chem. Chem. Phys. 1999, 1, 723-736. [CrossRef]

40. Okazaki, S.; Kurimata, M.; Iizuka, T.; Tanabe, K. The Effect of Phosphoric Acid Treatment on the Catalytic Property of Niobic Acid. Bull. Chem. Soc. Jpn. 1987, 60, 37-41. [CrossRef]

41. Yang, F.; Liu, Q.; Bai, X.; Du, Y. Conversion of biomass into 5-hydroxymethylfurfural using solid acid catalyst. Bioresour. Technol. 2011, 102, 3424-3429. [CrossRef] [PubMed]

42. Nakajima, K.; Noma, R.; Kitano, M.; Hara, M. Titania as an Early Transition Metal Oxide with a High Density of Lewis Acid Sites Workable in Water. J. Phys. Chem. C 2013, 117, 16028-16033. [CrossRef]

43. Noma, R.; Nakajima, K.; Kamata, K.; Kitano, M.; Hayashi, S.; Hara, M. Formation of 5-(Hydroxymethyl)furfural by Stepwise Dehydration over $\mathrm{TiO}_{2}$ with Water-Tolerant Lewis Acid Sites. J. Phys. Chem. C 2015, 119, 17117-17125. [CrossRef]

44. Li, G.; Pidko, E.A.; Hensen, E.J.M.; Nakajima, K. A Density Functional Theory Study of the Mechanism of Direct Glucose Dehydration to 5-Hydroxymethylfurfural on Anatase Titania. ChemCatChem 2018, 10, 4084-4089. [CrossRef]

45. Jadhav, H.; Pedersen, C.M.; Sølling, T.; Bols, M. 3-Deoxy-glucosone in an Intermediate in the Formation of Furfurals from D-glucose. ChemSusChem 2011, 4, 1049-1051. [CrossRef]

46. Takagaki, A.; Goto, H.; Kikuchi, R.; Oyama, S.T. Silica-supported chromia-titania catalysts for selective formation of lactic acid from a triose in water. Appl. Catal. A Gen. 2019, 570, 200-208. [CrossRef]

(C) 2019 by the author. Licensee MDPI, Basel, Switzerland. This article is an open access article distributed under the terms and conditions of the Creative Commons Attribution (CC BY) license (http://creativecommons.org/licenses/by/4.0/). 